\title{
VARIETAL TRIAL OF RAINFED RICE GENOTYPES USING DIFFERENT NUTRIENT MANAGEMENTS AT CSU PIAT, CAGAYAN, PHILIPPINES
}

\author{
Neil Nemesio A. Baliuag* ${ }^{1}$ and Ricardo B. Casauay ${ }^{2}$ \\ 1,2 Cagayan State University (CSU) Piat Campus, Piat, Cagayan
}

\begin{abstract}
In the Philippines, rainfed rice is grown on about 1.3 million hectares or $33 \%$ of the total rice area of 4 million hectares. With unpredictable weather, highly variable and heterogenous soils, the evaluation of recommended location specific rainfed rice varieties was done at CSU Piat from 2013WS to 2014WS. Treatments were laid out in RCBD with three replications. Twelve sahod ulan varieties were evaluated for yield, yield components and agronomic traits. PSB Rc14 was used as the check variety for rainfed while PSB Rc82 and NSIC Rc222 as farmers preferred variety in the locality. Across seasons, results showed significant differences in yield which is attributed to varietal and genetic differences of materials tested. NSIC Rc284 obtained the highest mean yield (4.2 ton/ha) with medium maturity of 110.67 days. Second highest yielder were NSIC Rc288 and NSIC Rc276 (3.89 and 3.88 ton/ha) with maturity of 94 and 92 days respectively. These are the top 3 selections specifically adapted at CSU Piat condition. These results/selections provide farmers an option of increasing yield and income using the right rainfed variety even in highly variable rainfed ecosystem.
\end{abstract}

Keywords: Genotypes, rainfed, varieties, yield, yield components

\section{INTRODUCTION}

Rainfed lowland rice in Asia covers about 46 million ha or almost $30 \%$ of the total world rice area (Maclean et al., 2002). Rainfed lowland rice faces various biotic and abiotic stresses, such as drought, submergence, adverse soil conditions, pests, and weeds. These conditions cause low rice production affecting about one billion people that depends on rainfed lowland rice in South and Southeast Asia. Because of the low and unstable productivity levels, poverty is severe in communities largely dependent on rainfed rice.

In the Philippines, rainfed lowland rice is grown on about 1.3 million ha or $33 \%$ of the total rice area of 4 million ha. Important rainfed areas are located in the Cagayan Valley in Northern Luzon, in Iloilo province, and on the coastal plains of Visayas and Ilocos in Northern Luzon. Some of the rainfed environments have favorable conditions for rice similar to irrigated systems but a considerable part is constrained by drought, submergence and limited soil fertility. Even in this condition, rainfed farmers tend to use irrigated varieties in their field due to the norms that it can yield above the average of that of stress tolerant varieties regardless of abiotic stress. The common practices in nutrient management were also patterned in irrigated areas and sometimes tend to have a blanket application rate across farmer's field. The development of stress tolerant varieties for rainfed lowland rice has been given emphasis by breeders for farmers to use in stress-prone environment.

In terms of nutrient management, the continuous development of technology and ICT decision-tool created the Rice Crop Manager (RCM). This was developed by scientists and researchers as a crop management technology for fertilizer recommendation that will reach out farmers especially those in remote areas. Rice Crop Manager (RCM) which follows the principles of site specific nutrient management (SSNM), gives nutrient recommendations required by rice plant in both 
rainfed and irrigated ecosystem. RCM is an application that can be accessed via a smartphone or computer with internet connections. RCM provides advice after a farmer answers a series of questions. Then it allows an extension officer to save, print, or send to the farmer's phone via email or SMS the recommendations on nutrient, pest, weed and water managements, depending on the specific variety they used, their yield from the previous season and the site-specific conditions of their field. It puts the power of technology into action by helping farmers decide how to manage their rice crops better.

Moreover, farmers are using irrigated high yielding varieties (HYV) in the rainfed ecosystem with the belief that it can yield above average than stress tolerant varieties in the rainfed environment. This reason is more prone in the risk of crop failure when drought occurs in the early to mid-season. The gap between the yield of stress tolerant varieties and irrigated HYV is large when grown in favorable condition. However, RCM can enhance the yield and nutrient use efficiency of stress tolerant varieties in the rainfed environments. Rainfed varieties can have a comparable yield to high yielding irrigated varieties using RCM in the rainfed environment, hence, this study.

\section{OBJECTIVES OF THE STUDY}

Generally, the study aimed to evaluate the effects in the nutrient efficiency, yield and yield components of rainfed lowland rice varieties and high yielding varieties using the Rice Crop Manager (RCM), Rice Crop Manager plus (RCM+), Farmers Practice (FP), and Control (no fertilizer application). Secondly, to determine the best combination of variety and nutrient management options in the rainfed lowland ecosystem.

Specifically, the study aimed to determine the agronomic and yield performance of 12 rainfed lowland rice newly released varieties using different crop managements (i.e. Rice Crop Manager, Rice Crop Manager +, Farmers Practice, and Control) under CSU Piat condition in the following parameters: days to $50 \%$ flowering, days to maturity, plant height, tiller number, culm length, panicle length, 1,000 grain weight, and yield (tons/ha).

\section{SCOPE AND DELIMITATION}

This study was focused on the evaluation of nutrient efficiency, yield and yield components of rainfed rice tolerant varieties and high yielding varieties using $\mathrm{RCM}, \mathrm{RCM}+$, FP, and Control; and to determine the best combination of variety and crop management options in the rainfed lowland. It was conducted at Cagayan State University, Piat Campus specifically in the rainfed experimental farm last August 2014 to January 2015. The data gathered were confined to agronomic, yield components, and yield parameters of the 12 rainfed rice varieties plus 3 checks using four crop managements i.e. RCM, RCM+, FP, and Control.

\section{MATERIALS AND METHODS}

\section{Materials}

Fifteen diverse rice varieties were used in this study that included 12 rainfed lowland rice varieties i.e. NSIC Rc192, NSIC Rc272, NSIC Rc274, NSIC Rc276, NSIC Rc278, NSIC Rc280, NSIC Rc282, NSIC Rc284, NSIC Rc286, NSIC Rc288, NSIC Rc346, NSIC Rc348 including 3 checks i.e. PSB Rc14, PSB Rc82, PSB Rc222 (Table 1). PSB Rc14 served as rainfed lowland rice check, while, PSB Rc82 served as the most preferred variety by farmers in the locality and NSIC Rc222 served as the high yielding irrigated check.

The following agricultural supplies and equipments were used in the study: fertilizers such as 14-14-14 (N-P-K), 46-0-0 (N-P-K), and 0-0-60 (N-P-K); insecticides such as Karate and Prevaton; handtractor, carabao-drawn disc plough, harrowing equipments i.e. suyod; shovel, panabas, and scythe.

Measuring devices such as piezometers, Automatic Weather Data Logger (AWD), sensitive weighing balance, $200{ }^{\circ} \mathrm{C}$ capacity oven, 1.5 meter stick, rulers, sacks, paper bags, cloth bags, net bags, shipping tags, record book, pencils, ballpens, and pentel pens.

\section{Methods}

The whole experimental area $\left(4,000 \mathrm{~m}^{2}\right)$ was laid out following the Split Plot in Randomized Complete Block design with three replications. 
The 15 diverse varieties evaluated were assigned as main plots (Factor A) while the four crop managements were assigned as sub-plots (Factor B). Each crop management was replicated thrice while the varieties evaluated were replicated per crop management. The following treatments evaluated were:

\begin{tabular}{lcc}
\hline \multicolumn{2}{l}{ FACTOR A = FIFTEEN RAINFED LOWLAND RICE VARIETIES (MAIN PLOT) } \\
\hline V1 = NSIC Rc192 & V6 = NSIC Rc280 & V11 = NSIC Rc346 \\
V2 = NSIC Rc272 & V7 = NSIC Rc282 & V12 = NSIC Rc348 \\
V3 = NSIC Rc274 & V8 = NSIC Rc284 & V13 = PSB Rc14 rainfed check \\
V4 = NSIC Rc276 & V9 = NSIC Rc286 & V14 = PSB Rc82 farmers prefered variety \\
V5 = NSIC Rc278 & V10 = NSIC Rc288 & V15 = PSB Rc222 high yielding irrigated \\
\hline
\end{tabular}

FACTOR B = CROP MANAGEMENTS (SUB-PLOT)

$\mathrm{RCM}=$ Rice Crop Manager $\quad$ FP = Farmers Practice

$\mathrm{RCM}+=$ Rice Crop Manager+ $\quad$ Control = No fertilizer application

There were 180 plots with dimensions of $4 \times 5$ meters each plot. Small paddy bunds (6 inches) were constructed to separate each plot (variety) within any crop management. Large paddy bunds (1 meter) were provided to separate Crop Managements (RCM, $\mathrm{RCM}+$, FP, Control) within a replication serving as blocks. Larger paddy dikes were constructed to separate each replication $(2.0 \mathrm{~m})$.

To minimize experimental errors, blocking orientation followed the slope soil gradient of the experimental area such that all treatments (Factor A and $\mathrm{B}$ ) will be exposed to the same environments (Figure 1).

Representative sample (RS) plants for the yield component data were randomly assigned within each plot just beside the grain field area. Each RS plant was marked with stakes with ID number on it to facilitate data gathering. Grain yield were derived from the inner most rows consisting of 125 hill or $5 \mathrm{~m}^{2}$. Agronomic data such as plant height, culm length, panicle length, and tiller number were derived from the inner rows each plot excluding 0.6 meter end rows.

\section{Data Analysis}

All agronomic yield and yield components data were analysed using the Statistical Tool for Agricultural Research specifically the analysis of variance (AnoVa) and comparison between treatment means.

\section{Securing of Planting Materials}

The 15 varieties of rice used in this study were provided by the International Rice research Institute (IRRI) and Philippine Rice Research (PhilRice) in collaboration with Cagayan State University (CSU) College of Agriculture at Piat Cagayan.

\section{Land Preparation and Layout}

An area of 4,000 m2 was used in this study. The area was thoroughly ploughed and harrowed twice at weekly intervals to hasten the decomposition of weeds and to attain proper soil tilt.

After the field was prepared, it was divided into three equal blocks for the replication with a pathway of two meter between replication. Furthermore, each replication was divided into four equal blocks for the four crop managements i.e. RCM, RCM+, FP, Control. Lastly, the four equal blocks (4 crop managements) were further subdivided into fifteen 
equal plots measuring $4 \mathrm{~m} \times 5 \mathrm{~m}$ or $20 \mathrm{~m} 2$ each variety.

\section{Seedbed preparation and Sowing of the Seeds}

An area of $75 \mathrm{~m}^{2}$ was utilized for seedbed. It was prepared thoroughly by paddling the area and after which it was levelled. The seedbed was subdivided into 15 measuring $1 \mathrm{~m} \times 5 \mathrm{~m}$ for the varieties. The seedbed was elevated with canals provided around the bed to drain excess water when there is heavy down pour of rain.

The seeds were soaked in clean water for 24 hours and incubated for another 24 hours to ensure good and uniform germination. The pre-germinated seeds were sown properly on the prepared seedbed.

\section{Pulling the Seedling}

Seedlings were carefully uprooted 21 days after sowing. The roots were washed and bundled in 12 bundles each seedbed for each varieties.

\section{Transplanting}

Before transplanting, the experimental area was leveled and paddy bunds were provided in the lay out to separate each plot (variety) being evaluated.

The seedlings were transplanted at a distance of 20 $\mathrm{cm}$ x $20 \mathrm{~cm}$ between hills with 2 seedlings per hill. It was transplanted September 03-05 2014.

\section{Water Management}

The plants were irrigated as the need arises or when the perch water table met the critical level. Equal amount of water were given per plot to avoid bias and experimental errors.

\section{Fertilizer Application}

Commercial fertilizers were applied in blanket application following the soil analysis recommendation (Table 2).

The amount of fertilizer applied at basal for Famers practice was $300 \mathrm{~g}$ of 14-14-14 per plot and $300 \mathrm{~g}$ of 46-0-0 was applied 30 days after transplanting. During panicle initiation $150 \mathrm{~g}$ of urea was applied.

The amount of fertilizer applied at basal for Rice Crop Manager was $300 \mathrm{~g}$ of 14-14-14 per plot and $100 \mathrm{~g}$ of 46-0-0 was applied 30 days after transplanting. During panicle initiation $150 \mathrm{~g}$ of urea was applied.

The amount of fertilizer applied at basal for Rice Crop Manager plus (RCM+) was $350 \mathrm{~g}$ of 14-14-14 per plot and $150 \mathrm{~g}$ of 46-0-0 was applied 30 days after transplanting. During panicle initiation $150 \mathrm{~g}$ of urea was applied.

\section{Control of pest and Diseases}

Appropriate insecticides were sprayed when insect pests and diseases were observed following the recommendation from the label of the insecticide.

\section{Harvesting}

Harvesting was done when $80 \%$ of the plants showed signs of maturity. Harvesting was done using scythe. The schematic diagram of the harvest area per plot is shown below: 


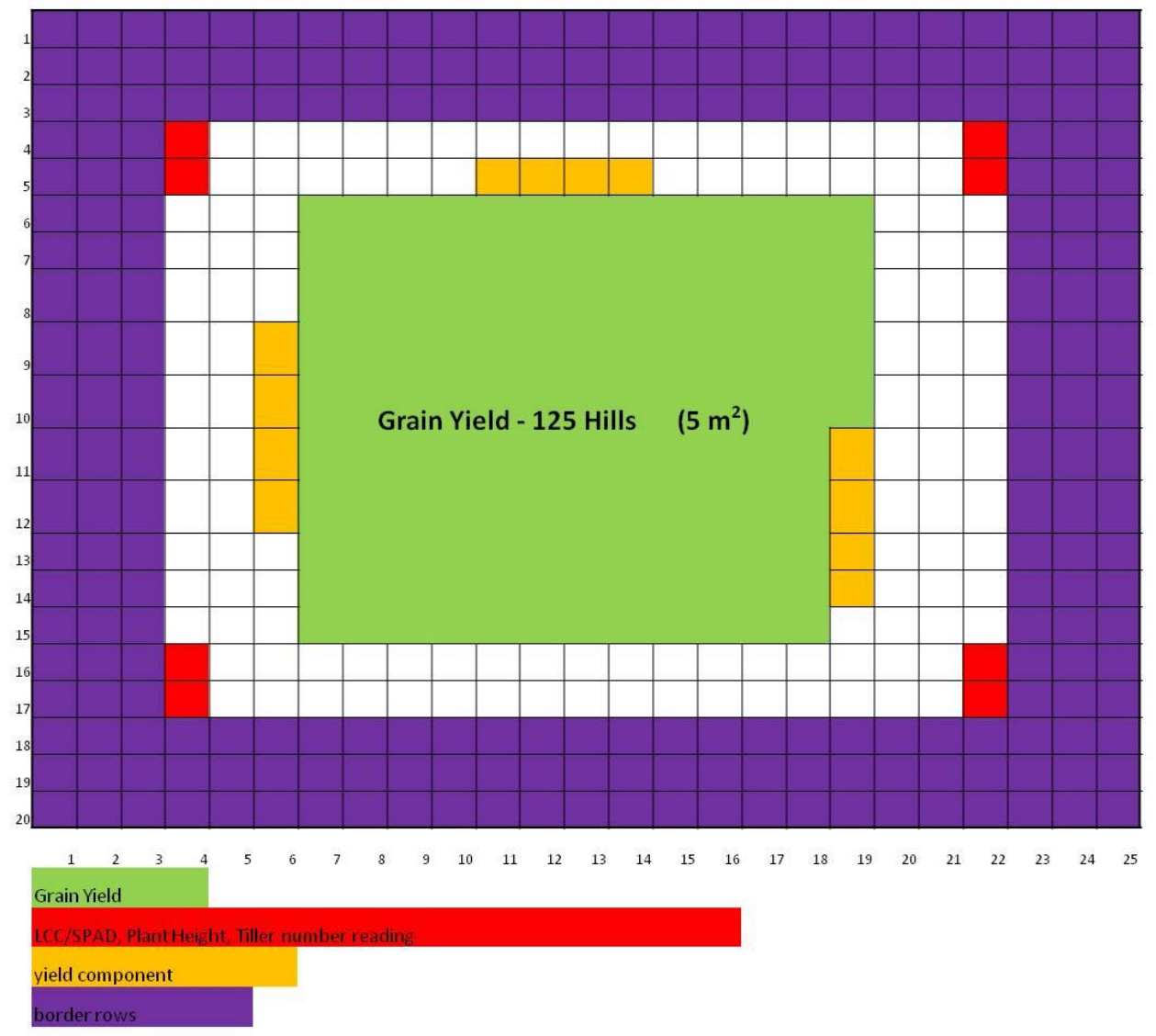

\section{Threshing}

After harvesting, it was threshed manually inside the net bags. The seeds were cleaned with moderate wind to avoid blowing away the half-filled grains.

\section{Drying}

The seeds were sundried in the concrete pavement wherein the seeds were placed in a cloth bag to avoid mixing seeds. Furthermore, it was oven dried to attain uniform moisture content of $14 \%$.

\section{Statistical tool used}

The Statistical Tool for Agricultural Research was used in the analysis of variance (ANOVA) using 5\% and $1 \%$ level of significance. The least significance difference at 5\% (LSD 0.05) was used to compare treatments.

\section{Data Gathered}

Number of days to flower

Number of days to maturity
Average Plant height at maturity $(\mathrm{cm})$ - the height of the plants was taken from the representative sample plants, measured from the base up to tips of the leaves.

Average tiller number - this was done by counting the total number of tillers from each representative sample plant and divided it by twelve (12) to get the average tiller number.

Average culm length $(\mathrm{cm})$ - this was taken from representative sample plants, measured from the base up to the above flag leaf at the lowest attachment of the spikelet

Average panicle length - this was taken from the representative sample plants outside the harvest area, this was done by measuring the above flag leaf at the lowest attachment of the spikelet up to the tip of the most spikelet

Computed yield tons per hectare - all the grains harvested from the harvest area per crop management were weighed and projected in tons/ha. 


\section{RESULTS AND DISCUSSION}

\section{Number of Days to Flower}

The average number of days to flower of the different rainfed rice genotypes across four crop managements tested i.e. Control, FP, RCM and $\mathrm{RCM}+$ is presented in Figure1a. Highly significant differences on average number of days to flower were observed among the different rainfed rice genotypes tested. Results further revealed that among the different rice genotypes evaluated, NSIC RC 348 was the earliest to flower with a mean of 58.33 days after sowing (DAS). This was followed by PSB Rc14 which flowered at 62 DAS. NSIC Rc192, 272, and 274 flowered at 65 DAS. NSIC Rc276 flowered at 68 DAS, while, NSIC Rc282 and PSB Rc82 had flowered similarly at 75.41 DAS. The high yielding irrigated variety (NSIC Rc222) flowered at 76 DAS, followed by NSIC Rc280 and 286 which flowered at 77.41 DAS. However, the longest days to flower was NSIC Rc284 with a mean of 80.91 DAS.

Comparison among treatment means (CATM) shows that NSIC Rc348 is significantly different from all the other rice genotypes. PSB Rc14, NSIC Rc192, 272, 274, 346 and 278 did not show significant difference from each other, though significant difference was noted when compared to the remaining rice genotypes. Likewise, statistical difference was observed between NSIC Rc288 and 278. On the other hand, NSIC Rc282, 222, PSB Rc82, NSIC Rc280 and 286 did not differ significantly with each other, but significant difference was observed when they were compared with NSIC Rc284.

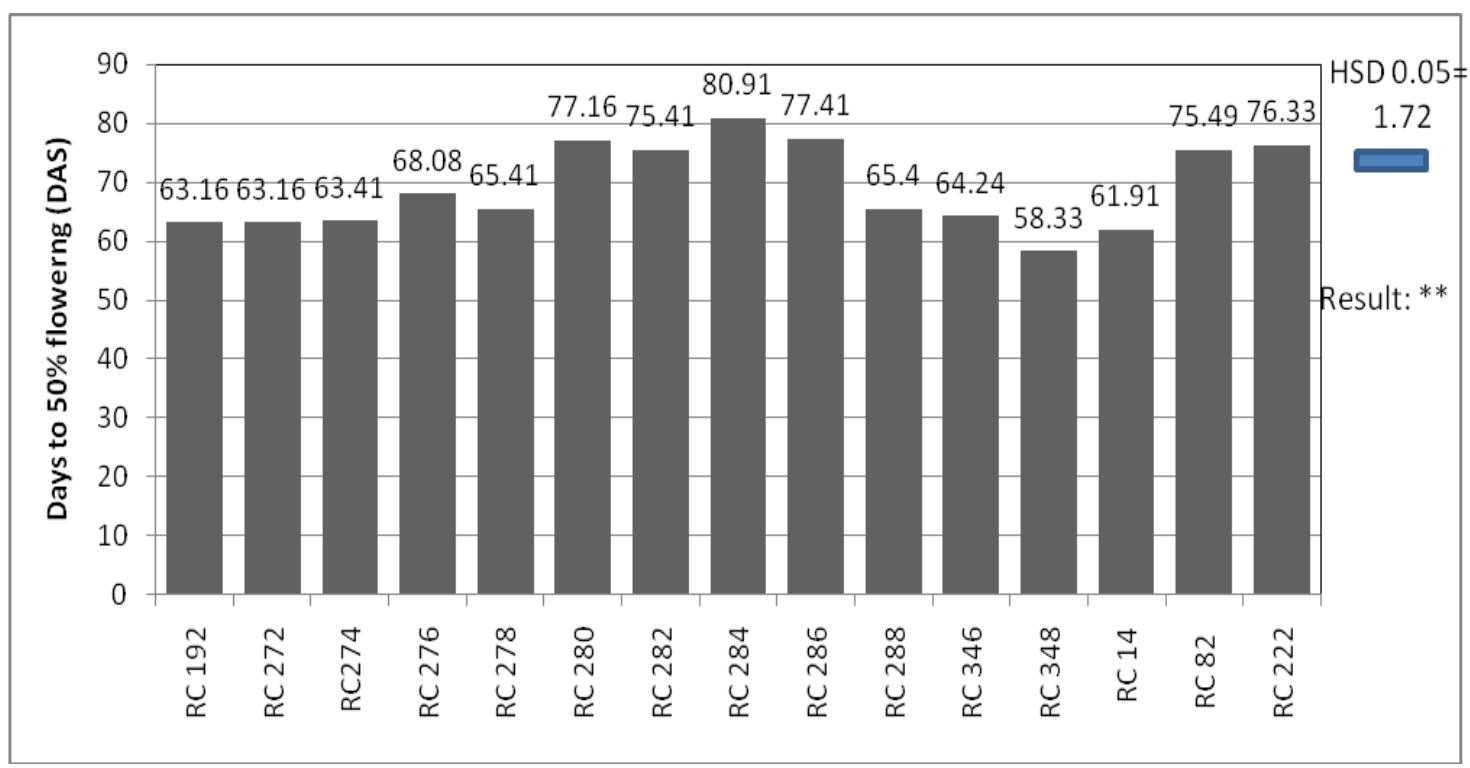

Figure1a: Number of days to flower of the different rainfed rice genotypes across four crop managements i.e. Control, FP, RCM, and RCM+. Where: FP=Farmers Practice, RCM=Rice Crop Manager, RCM+ = Rice Crop Manager plus. CSU-Piat, Cagayan, January 2015.

Figure $1 \mathrm{~b}$ presents the number of days to flower of the different rice genotypes subjected to different crop managements. Plant exposed to the farmers' practice (FP) was the earliest to produce flowers at 68 DAS, followed by plants in the control treatment and RCM with the same flowering of 69 DAS, and $\mathrm{RCM}+$ with flowering days of 78 DAS. Despite slight differences, analysis of variance showed significant differences between crop management treatments. Similar result was obtained by Chang (__ , that application of nitrogen during panicle initiation delayed flowering.

The interaction between variety and crop management revealed significant difference. Results implies that the different rice genotypes responded differently when exposed to the different crop management treatments. 


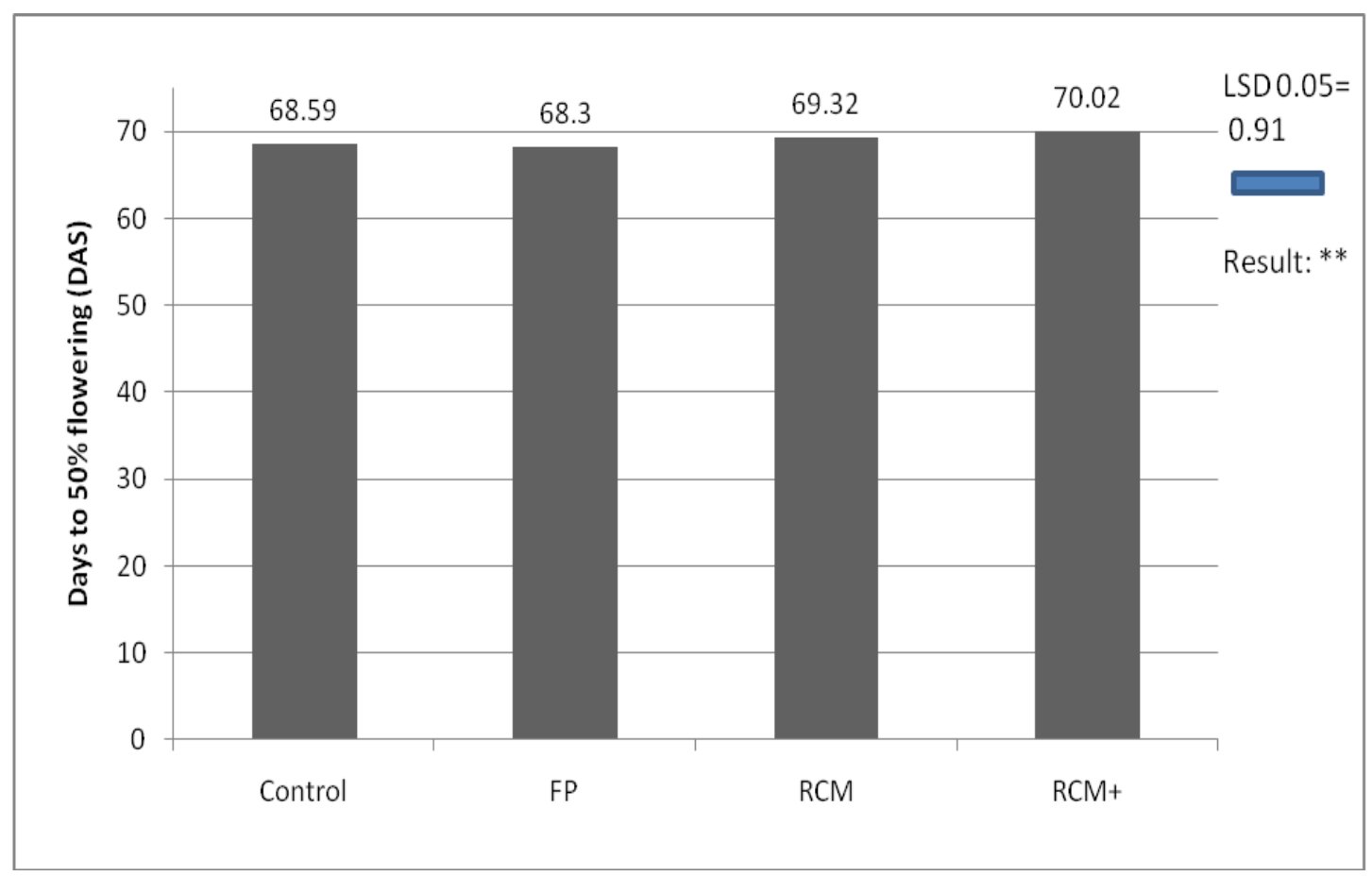

Figure1b: Average number of days to flower of different rainfed rice genotypes subjected to the different crop managements i.e. Control, FP, RCM, and RCM+. Where: FP=Farmers Practice, RCM=Rice Crop Manager, RCM+ = Rice Crop Manager plus. CSU-Piat, Cagayan, January 2015.

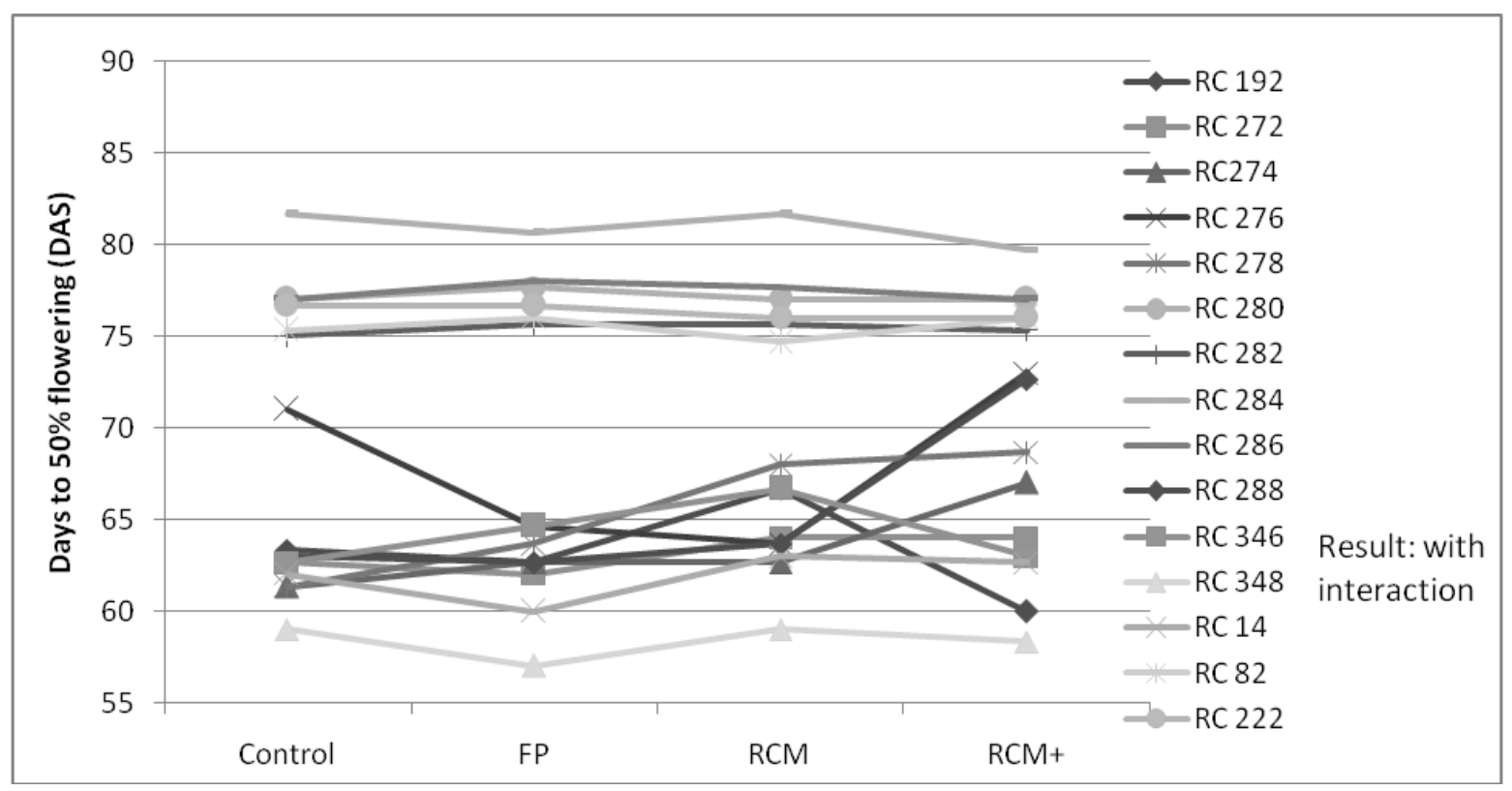

Figure 1c: Interaction of the different rainfed rice genotypes and crop managements on the number of days to flowering.

\section{Days to Maturity (DAS)}

The average number of days to maturity of the different rainfed rice genotypes across four crop managements tested i.e. Control, FP, RCM and
$\mathrm{RCM}+$ is presented in Figure2a. There exist highly significant differences on average number of days to mature between the different rainfed rice genotypes tested. Results further revealed that among the different rice genotypes evaluated, NSIC Rc348 was 
the earliest to mature with a mean of 88.33 DAS, followed by PSB Rc14 (rainfed check) which matured at 92 DAS. In addition, NSIC Rc192, 272, and 274 matured similarly at 95 DAS, and NSIC Rc276 matured at 98 DAS. NSIC Rc282 and the same as PSB Rc82 had matured 105.41 DAS. The high yielding irrigated check (NSIC Rc222) matured at 106 DAS, followed by NSIC Rc280 and 286 that flowered at 107.41 DAS. However, the longest day to mature was exhibited by the rainfed genotypeNSIC Rc284 with 110.91 DAS.

Comparison among treatment means (CATM) with respect to maturity showed that NSIC Rc348 is significantly different from all the other rice genotypes. However, PSB Rc14, NSIC Rc192, 272, 274, 346 and 278 did not show significant difference from each other, though significant difference was noted when compared to the remaining rice genotypes. Likewise, statistical difference was observed between NSIC Rc288 and 278. On the other hand, NSIC Rc282, 222, PSB Rc82, NSIC Rc280 and 286 did not differ significantly with each other, but significant difference was observed when they were compared with NSIC Rc284.

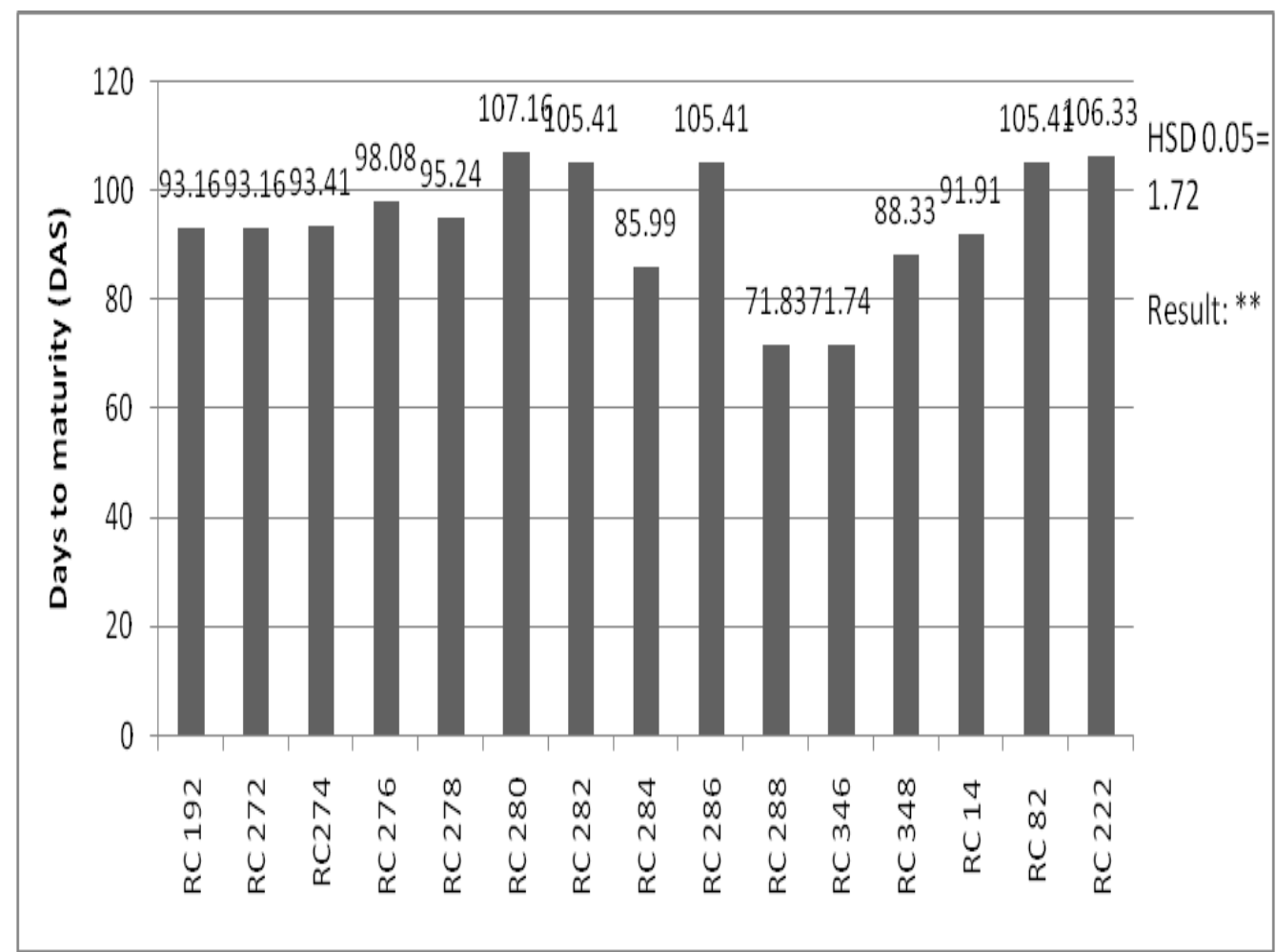

Figure 2a: Number of days to maturity of the different rainfed rice genotypes across four crop managements i.e. Control, FP, RCM, and RCM+. Where: FP=Farmers Practice, RCM=Rice Crop Manager, RCM+ = Rice Crop Manager plus. CSU-Piat, Cagayan, January 2015.

The average number of days to mature of the different rice genotypes subjected to different crop managements is presented in Figure 1b. Plant exposed to the farmers' practice (FP) was the earliest to mature at $98 \mathrm{DAS}$, followed by plants in the control treatment and RCM with the same maturity of 99 DAS, and RCM+ with maturity of 108 DAS. Moreover, analysis of variance showed highly 
significant differences between crop management treatments. Similar result was obtained by Chang (__ ), that application of nitrogen during panicle initiation delayed flowering and maturity of plants tested.
The interaction between variety and crop management revealed highly significant difference. Results imply that the different rice genotypes responded differently when exposed to the different crop management treatments.

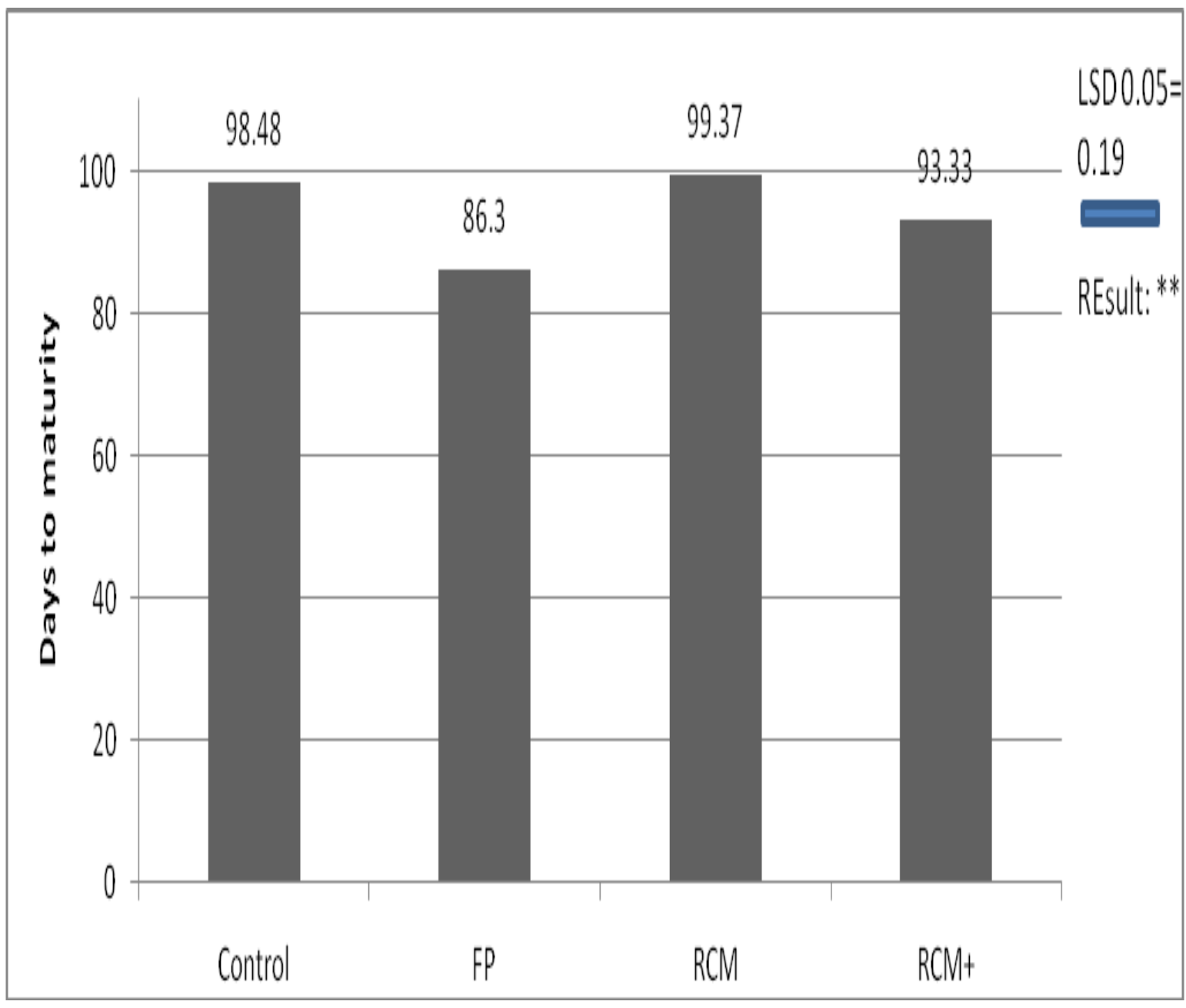

Figure 2b: Average number of days to maturity of different rainfed rice genotypes subjected to the different crop managements i.e. Control, FP, RCM, and RCM+. Where: FP=Farmers Practice, RCM=Rice Crop Manager, $\mathrm{RCM}+=$ Rice Crop Manager plus. CSU-Piat, Cagayan, January 2015. 


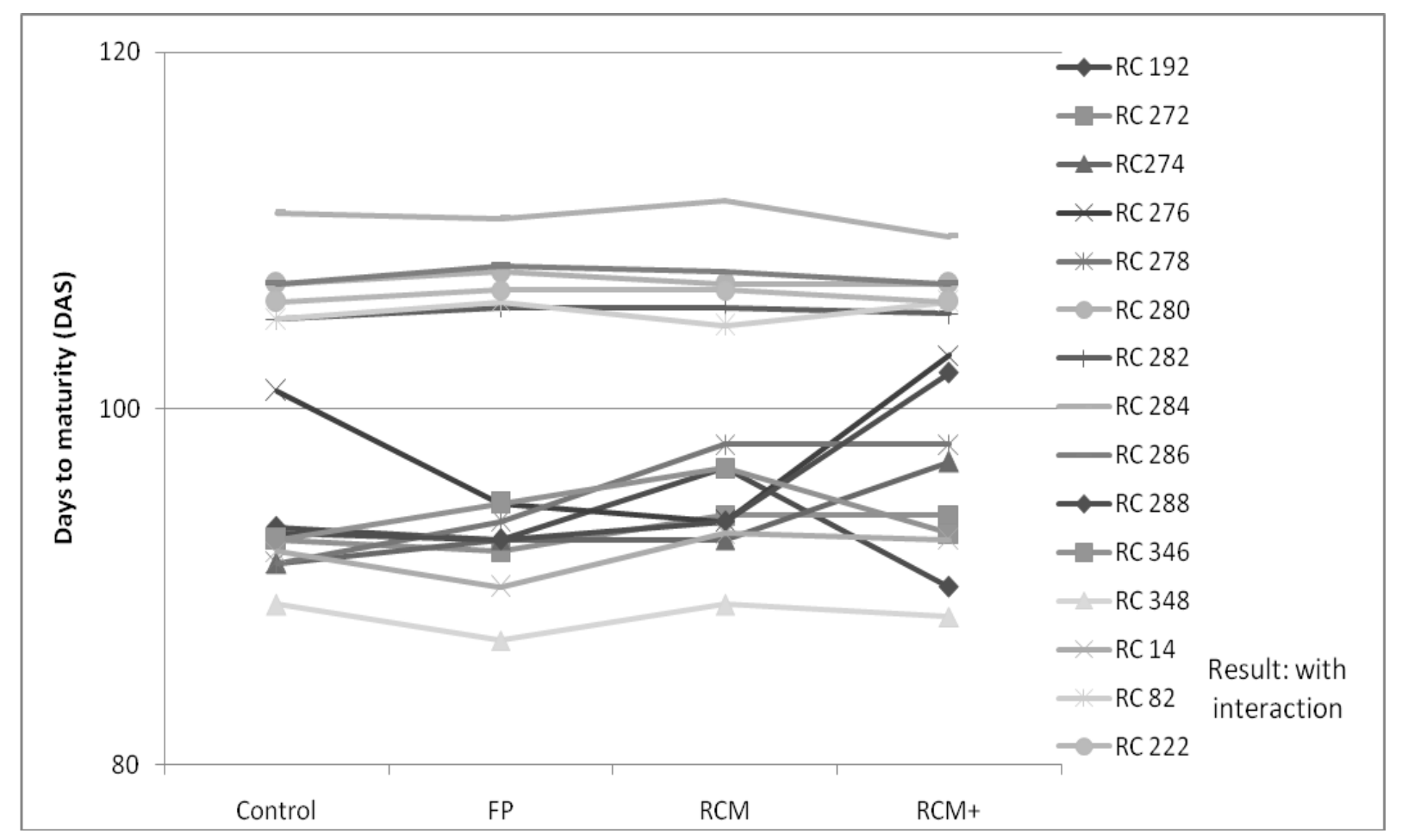

Figure 2c: Interaction of the different rainfed rice genotypes and crop managements on the number of days to maturity.

\section{Plant height (cm)}

Figure $3 \mathrm{a}$ shows the height of the 12 rainfed rice genotypes including 3 checks (PSB RC 14, PSB RC 82 and PSB RC 22) across the four crop management (Control, FP,RCM and RCM+). Analysis of variance revealed that there exists highly significant difference among treatment means. NSIC RC 278 recorded the tallest plants with a mean of $95.92 \mathrm{~cm}$. This was followed by NSIC RC 348, NSIC RC 282, and PSB RC 222 with a range of $84.62 \mathrm{~cm}$ to 86.19 cm,. Plant varieties NSIC RC 192, NSIC RC 288, PSB RC182, NSIC RC 274,NSIC RC 280, NSIC RC 284, and NSIC RC 286obtained the shortest plants with a range of77.27 $\mathrm{cm}$ to $81.47 \mathrm{~cm}$. This observation may be depends on the characteristics and morphology of the plants (IRRI, 2007). It showed that different varieties differ in terms of height because each have their own agronomics characteristic. This result jive with the findings of Bartolome (1998), in his study entitled "The effect of spacing in the yield of two varieties of rice".

Figure $3 \mathrm{~b}$ shows the height $(\mathrm{cm})$ of the 12 rice genotypes in terms of the four crop management.
Analysis of variance revealed no significant difference between the four-crop management. This means that this four crop management has no effect in terms of plant height.

No interaction was obtainedbetween varieties and different nutrient management (Figure 3c). This means that application of fertilizer on the different varieties of rice has no impact. 


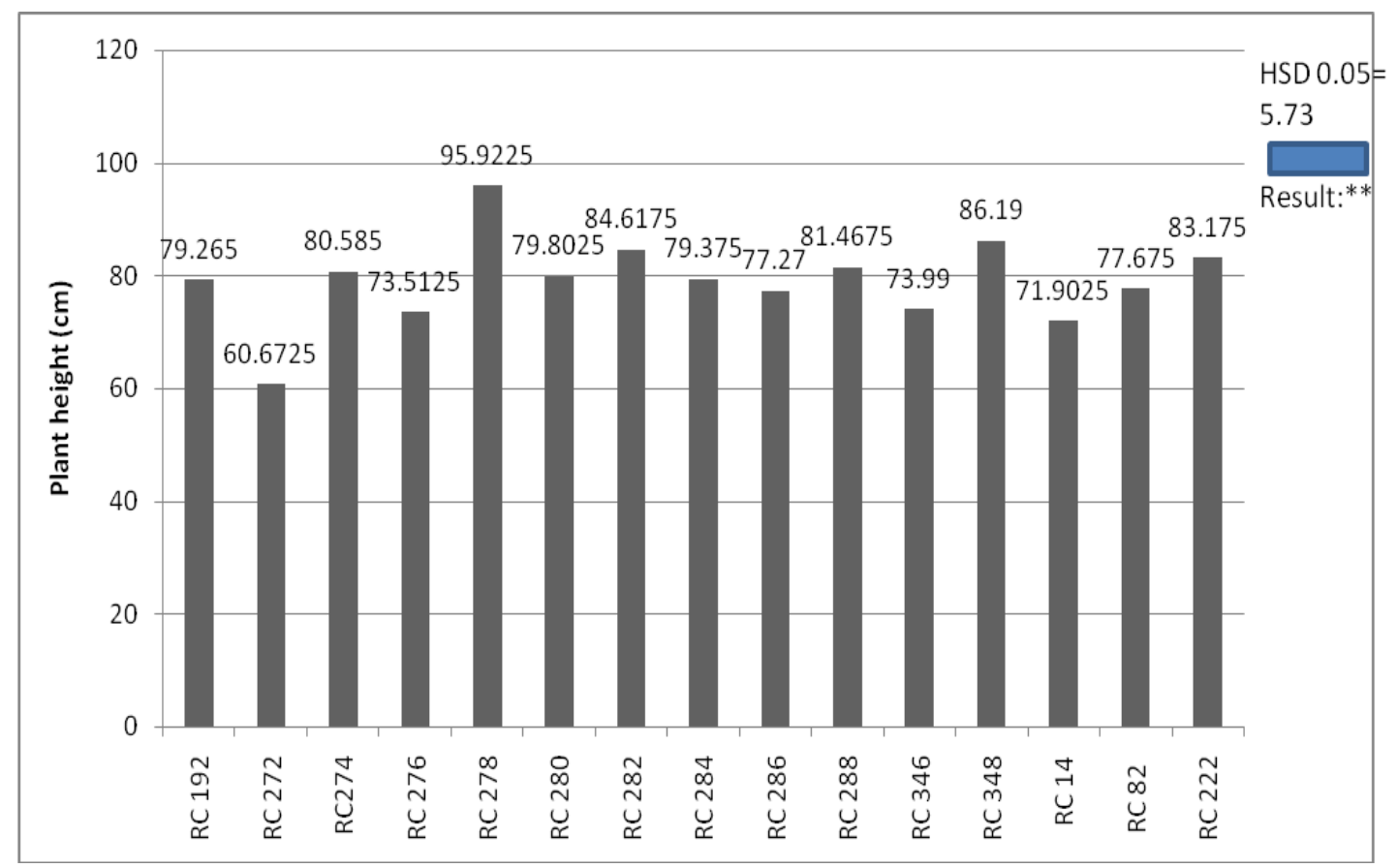

Figure 3a: The plant height performance of the 12 rainfed rice genotypes including 3 checks (PSB RC 14, PSB RC 82 and PSB RC 22) across the four crop management (Control, Farmers Practice,Rice Crop Manager and Rice Crop Manager+).

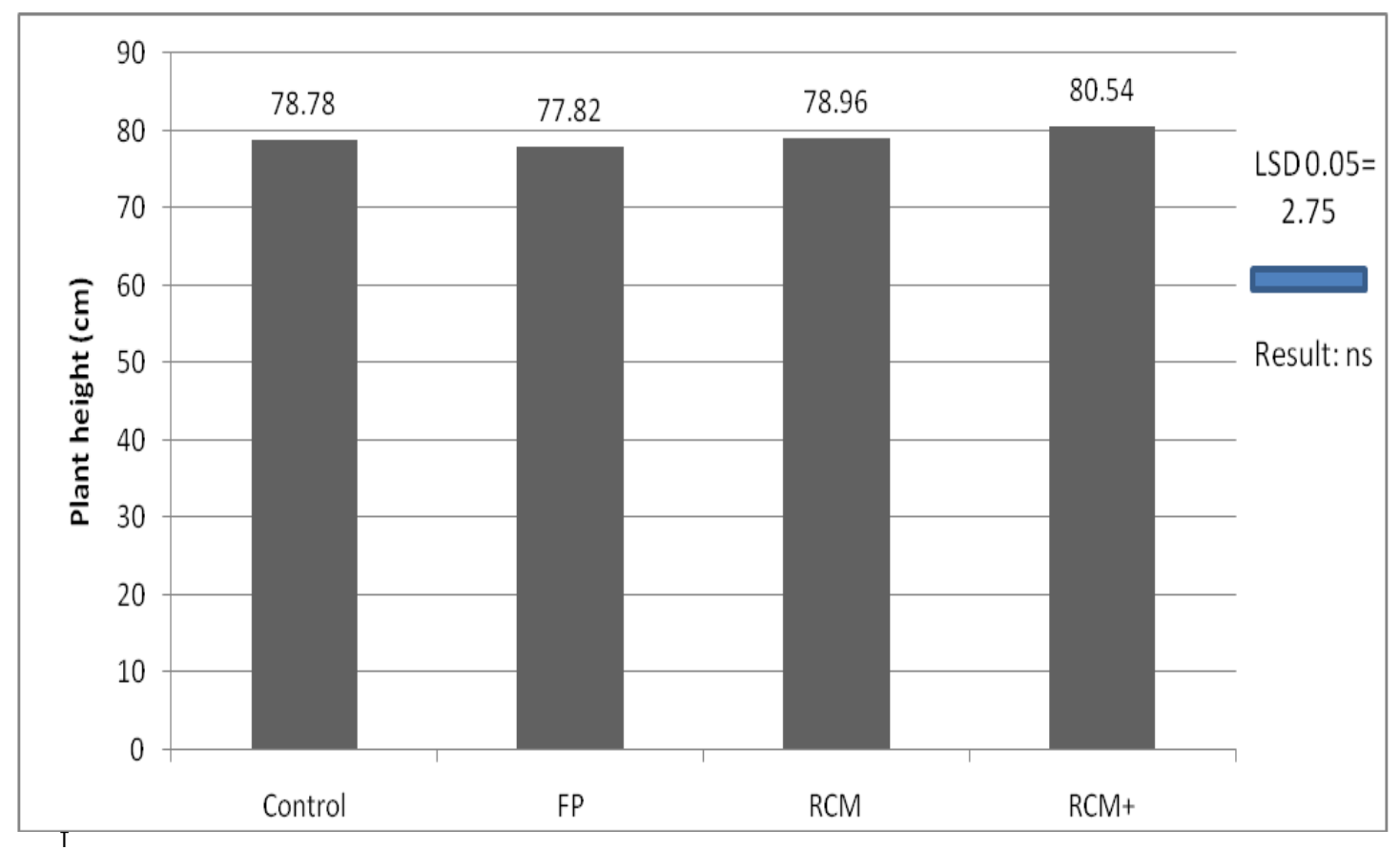

Figure 3b: Performance of the four crop management on plant height across the 12 rainfed rice genotypes including 3 checks (PSB RC 14, PSB RC 82 and PSB RC 222).Where FP:Farmers Practice, RCM: Rice Crop Manager, and RCM+:Rice Crop Manger plus. height performance of the 12 rainfed rice genotypes including 3 checks (PSB RC 14, PSB RC 82 and PSB RC 22) across the four crop management (Control, Farmers Practice,Rice Crop Manager and Rice Crop Manager+). 


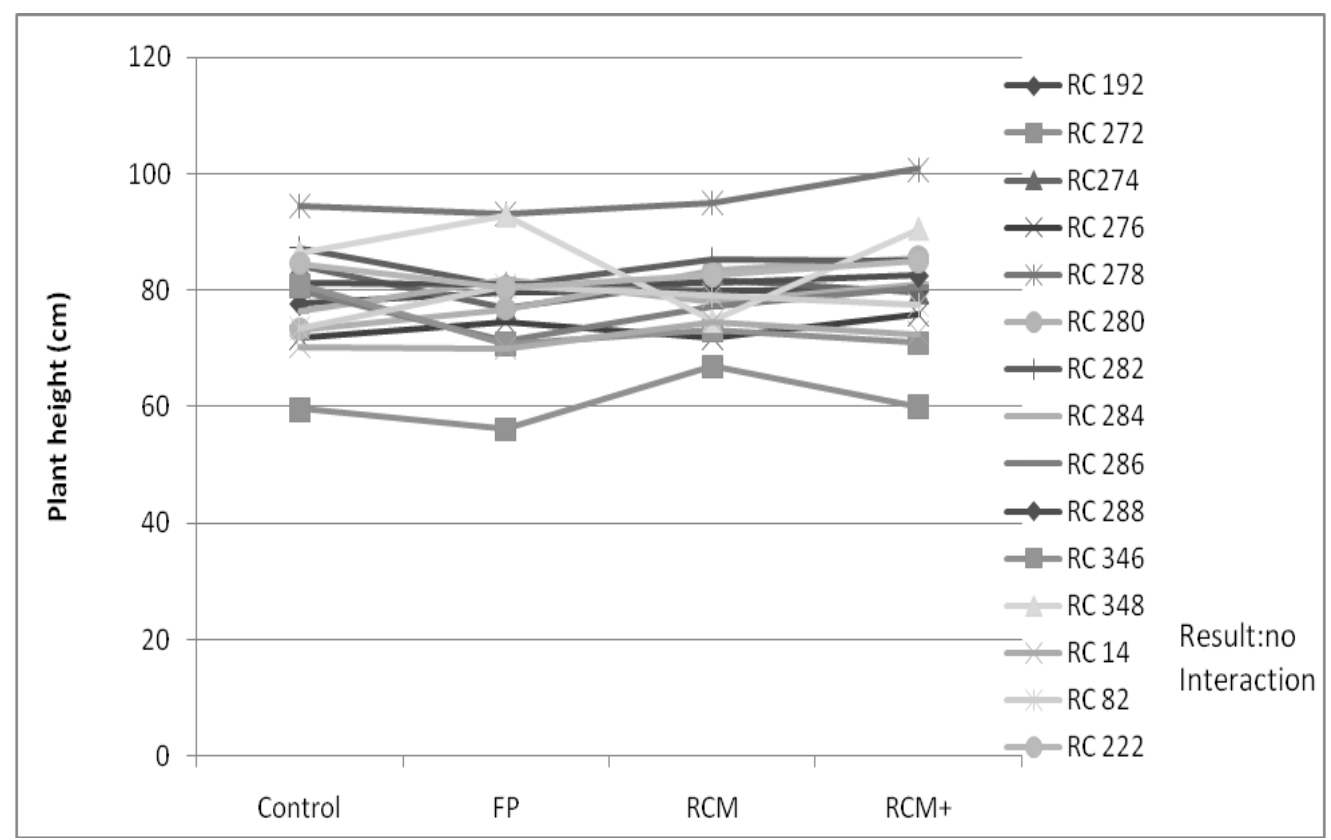

Figure 3c: Interaction of height at maturity of the 12 rainfed rice genotypes including 3 checks (PSB RC 14, PSB RC 82 and PSB RC 222) to four crop management (Control, Farmers Practice,Rice Crop Manager and Rice Crop Manager+).

\section{Tiller number}

Figure $4 \mathrm{a}$ shows the average tiller number of the 12 rainfed rice genotypes including 3 checks (PSB RC 14, PSB RC 82 and PSB RC 22) across the four crop management (Control, FP,RCM and $\mathrm{RCM}+$ ).Analysis of variance reveals highly significant difference among the varieties tested. NSIC RC $276(10.21 \mathrm{~cm})$ produce the most tiller number. This means that this variety was well adopted to CSU-Piat condition. It was followed by PSB RC 14 (9.37) that placed $2^{\text {nd }}$. PSB RC 222 NSIC RC 280, NSIC RC 346, PSB RC 82, NSIC RC 278 and NSIC RC 288 placed $3^{\text {rd }}$ ranked with a range of 8.02 to 8.02 . NSIC RC 272, NSIC RC282, NSIC RC
284, NSIC RC 286 and NSIC RC 192 placed $4^{\text {th }}$ rank with a range of 7.9 to 7.12 while NSIC RC 274 and NSIC RC 348 recorded the least number of tillers/plant with a mean of 6.9 and 6.8 .

On the other hand, no significant difference between crop management means. This means that the application of different rate of fertilizer has no impact on the number of tillers per plant produced.

Figure $4 \mathrm{c}$ shows no interaction existed from varieties to crop management in terms of tiller number of the 12 genotypes of rice tested. This means that different varieties tested follows the same respond to the different crop nutrient management. 


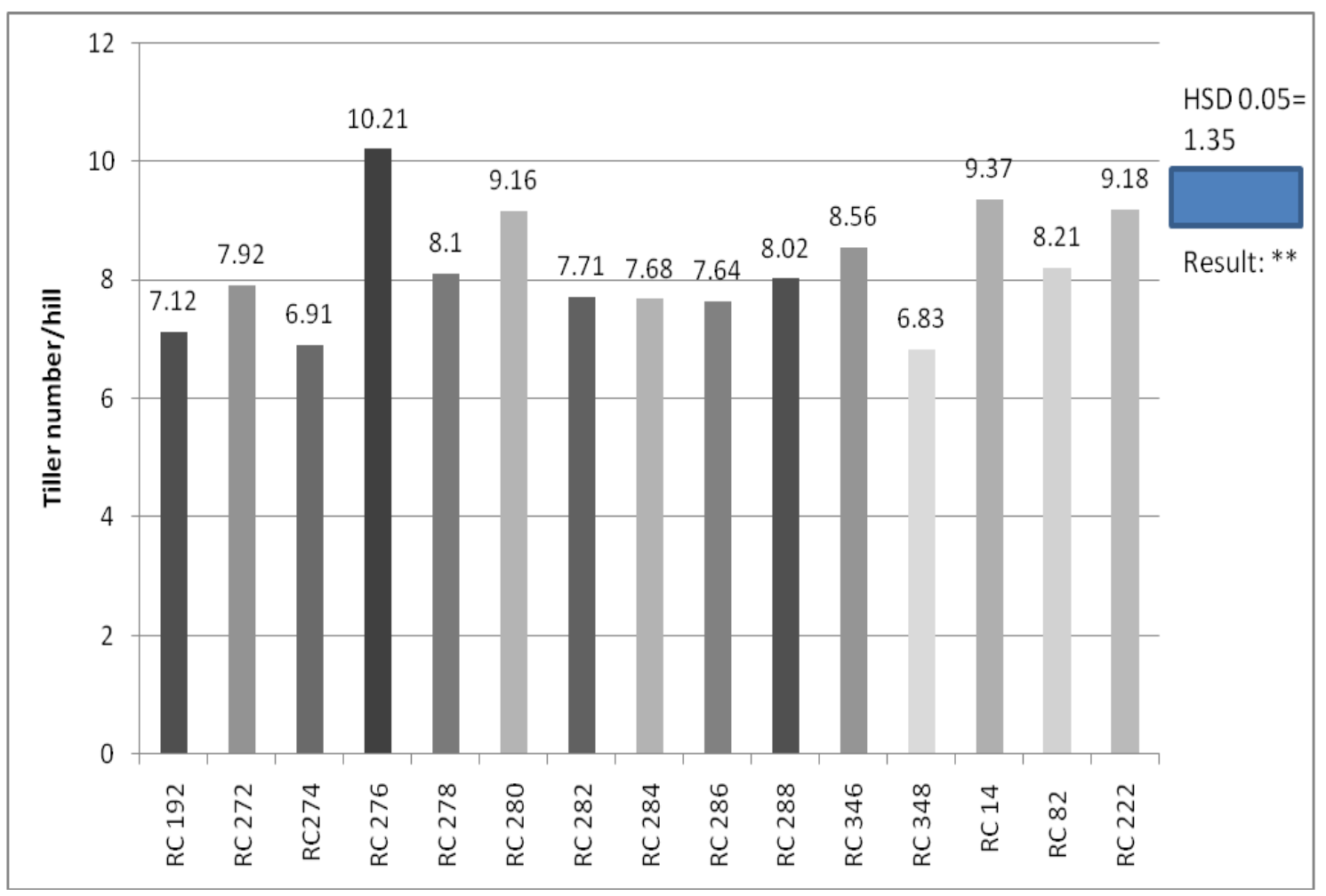

Figure 4a: The tiller number of the 12 rainfed rice genotypes including 3 checks (PSB RC14, PSB RC 82 and PSB RC 22) across the four crop managements (Control, Farmers Practice,Rice Crop Manager and Rice Crop Manager+).

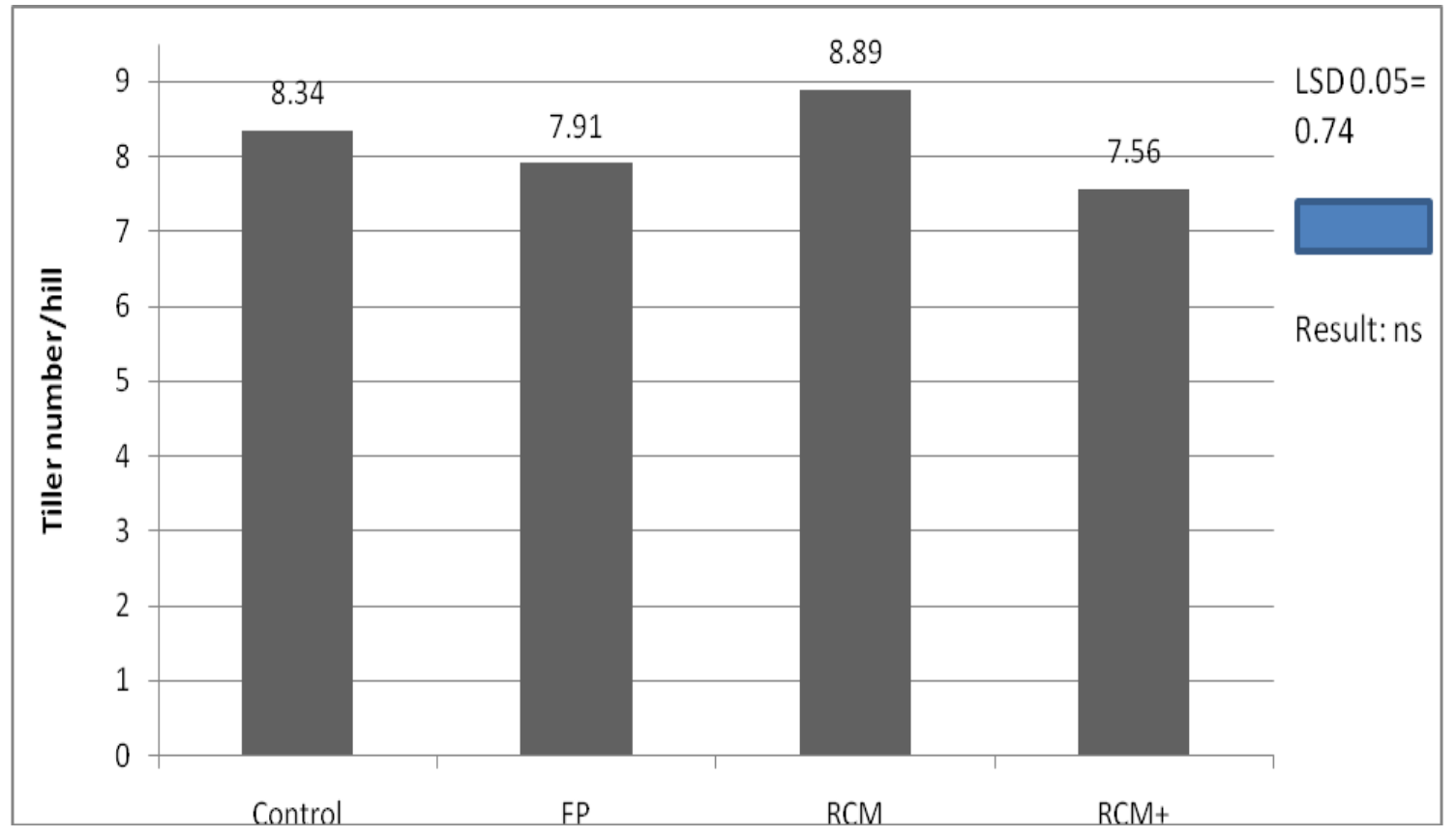

Figure 4b: Performance of the four crop management on tiller number across the 12 rainfed rice genotypes including 3 checks (PSB RC 14, PSB RC 82 and PSB RC 222). Where FP:Farmers Practice, RCM: Rice Crop Manager, and RCM+:Rice Crop Manger plus. 
Neil Nemesio A. Baliuag and Ricardo B. Casauay/Varietal trial of rainfed rice genotypes...

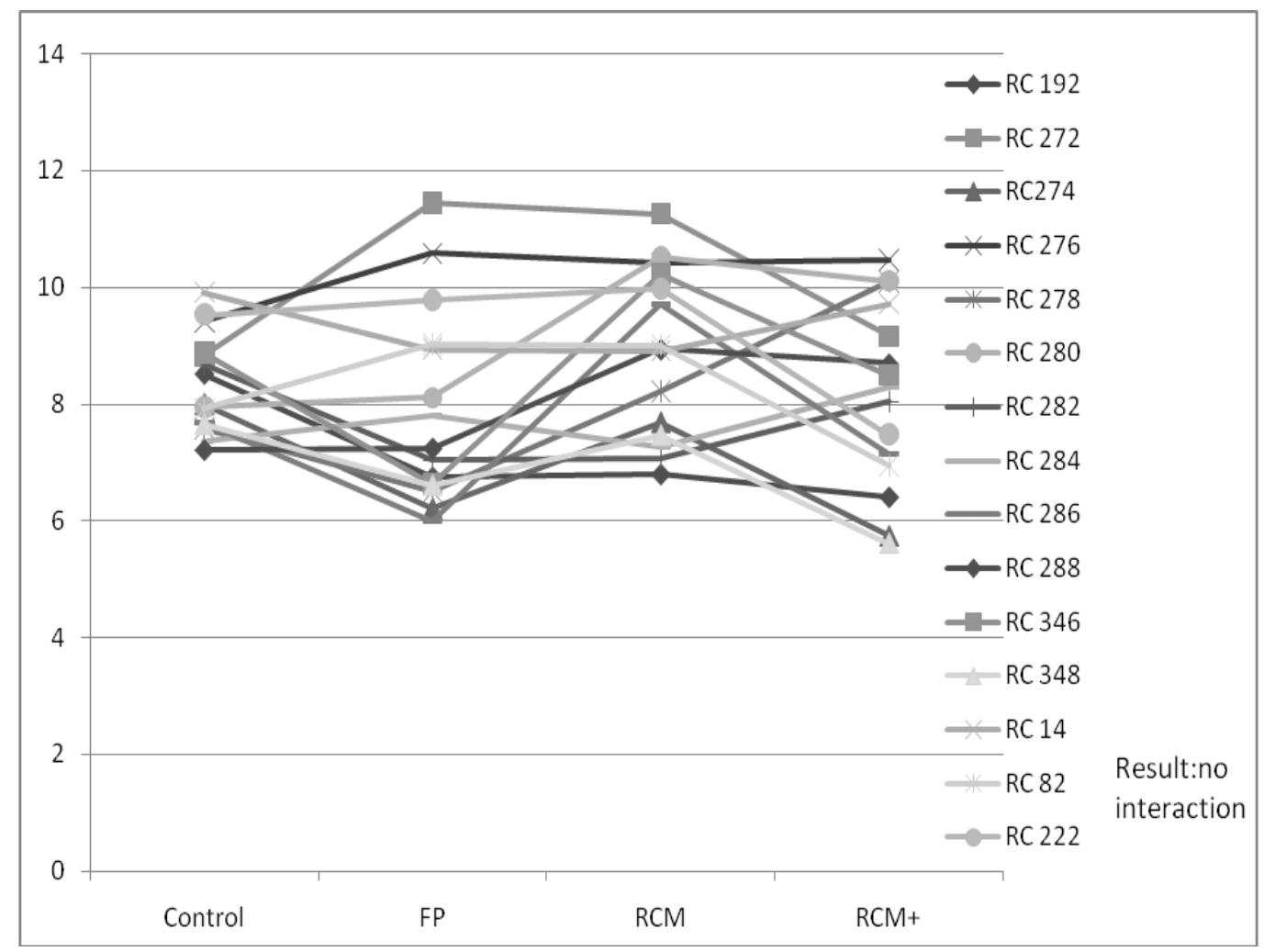

Figure 4c: Interaction of tiller number of the 12 rainfed rice genotypes including 3 checks (PSB RC 14, PSB RC 82 and PSB RC 22) to four crop management (Control, Farmers Practice,Rice Crop Manager and Rice Crop Manager+).

\section{Culm Length (cm)}

Figure 5a shows the culm lengthof the 12 rainfed rice genotypes including 3 checks (PSB RC 14, PSB RC 82 and PSB RC 22) across the four crop management (Control, FP,RCM and RCM+). Based on the result of the study there exist highly significant difference between the 15 varieties tested. Still this was attributed to the different characteristics of the rice varieties. Based on the comparison among variety means, NSIC RC 278 recorded to have the longest culm length with a mean of $71.81 \mathrm{~cm}$ followed by NSIC RC 348 of $64.43 \mathrm{~cm}$ and NSIC RC 282 of 62.89 that place $2^{\text {nd }}$ and $3^{\text {rd }}$ respectively $4^{\text {th }}$ ranker were NSIC RC 192, NSIC RC 288, PSB RC 82, PSB RC 222 and NSIC RC 280 since no significant difference existed between them.
On the other hand comparison among 4 crop management means revealed that there is no significant difference existed. This means that the rice plant tested respond to all crop nutrient management.

Figure $5 \mathrm{c}$ revealed that there is no interaction between variety and crop management. This means that 15 rice varieties follow the same respond to that of the four crop managements tested. 


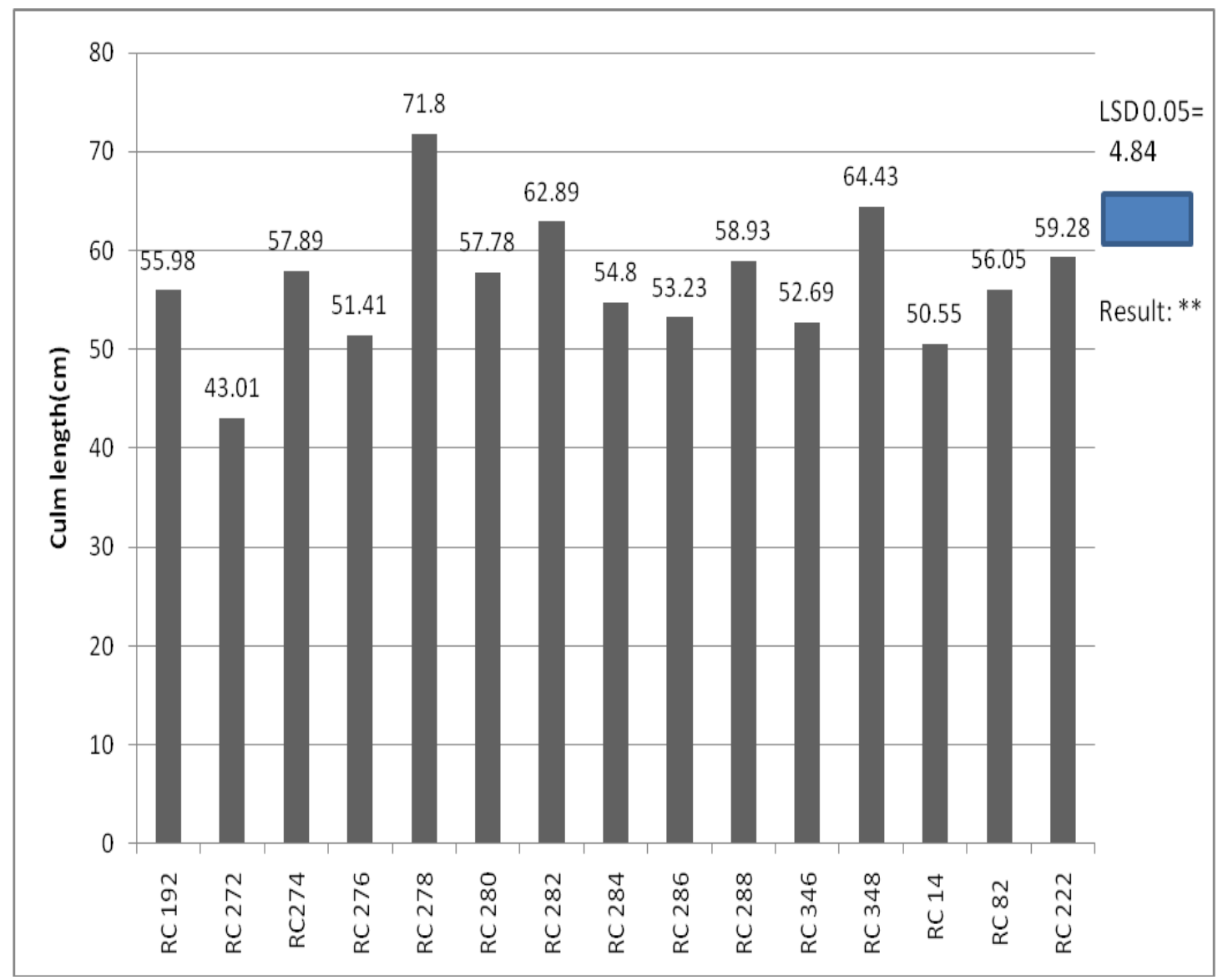

Figure 5a: The culm length performance of the 12 rainfed rice genotypes including 3 checks (PSB RC 14,PSB RC 82 and PSB RC 22) across the four crop management (Control, Farmers Practice,Rice Crop Manager and Rice Crop Manager+).

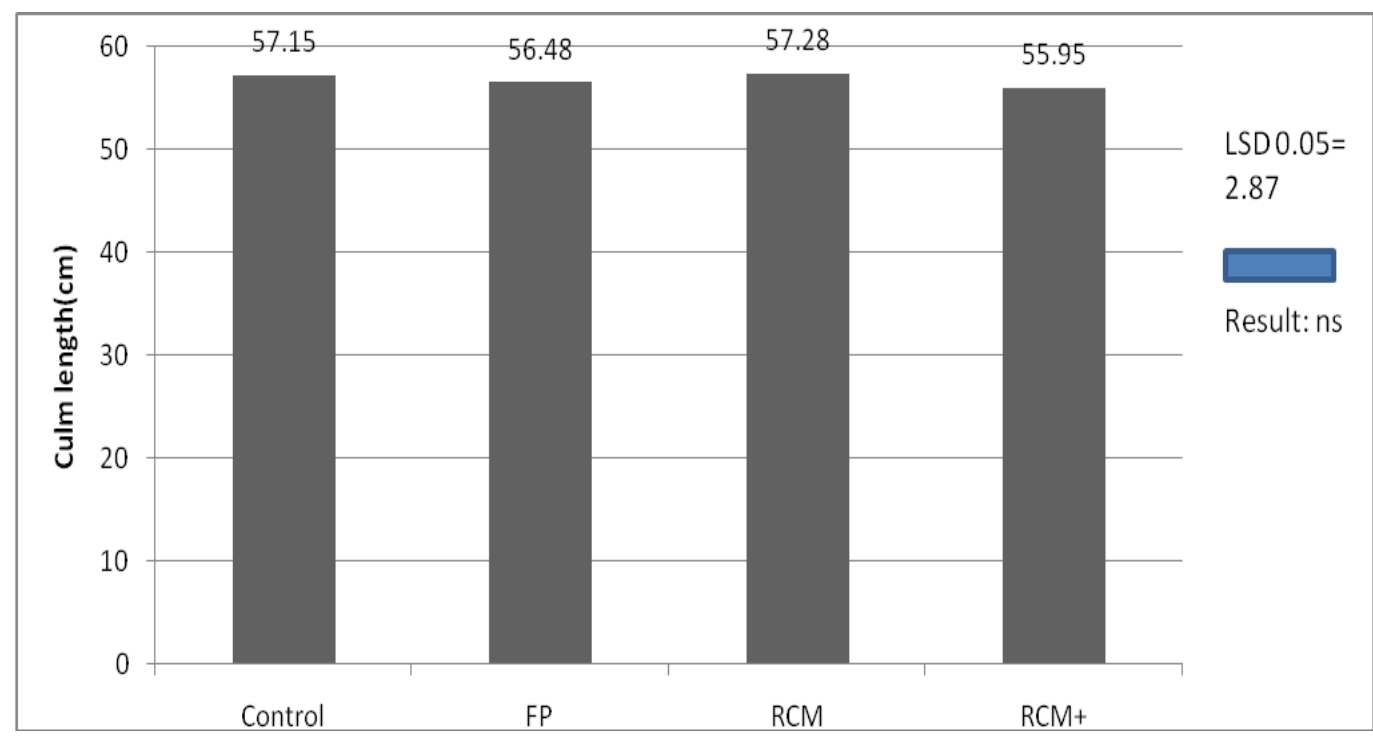

Figure 5b:Performance of the four crop management on culm length across the 12 rainfed rice genotypes including 3 checks (PSB RC 14, PSB RC 82 and PSB RC 222). Where FP:Farmers Practice, RCM: Rice Crop Manager, and RCM+:Rice Crop Manger plus. 


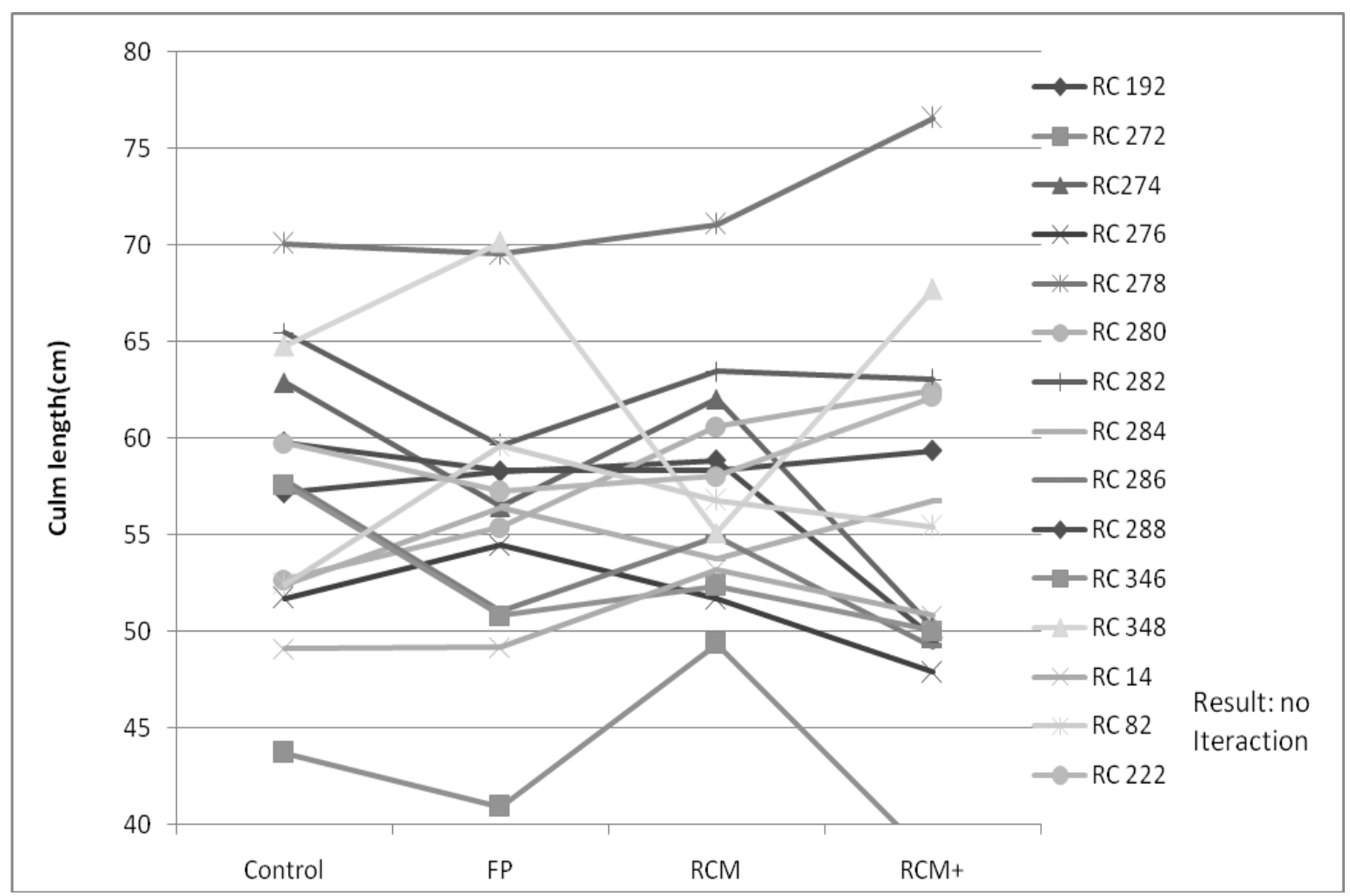

Figure 5c: Interaction of the 12 rainfed rice genotypes including 3 checks (PSB RC 14, PSB RC 82 and PSB RC 22 ) to four crop management (Control, FP, RCM and $\mathrm{RCM}+$ ) on culm length performance.

\section{Panicle Length}

Figure 5a shows the average panicle length of the 12 rainfed rice genotypes including 3 checks (PSB RC 14, PSB RC 82 and PSB RC 22) with four crop management (Control, FP,RCM and RCM+). Analysis of variance reveals that there exist highly significant differences between varieties means. NSIC RC 284, NSIC RC 278 , and NSIC RC 286 obtained the longest panicle of $23.9 \mathrm{~cm}, 24.76 \mathrm{~cm}, 24.1$ $\mathrm{cm}, 24.03 \mathrm{~cm}$ and $23.9 \mathrm{~cm}$. This was followed by PSB RC 222, NSIC RC 288,NSIC RC 192, NSIC RC274, NSIC RC276, NSIC RC 280,NSIC RC 282,PSB RC 82, NSIC RC 348, PSB RC 14 and NSIC RC346 with a range of $23.89 \mathrm{~cm}$ to $21.35 \mathrm{~cm}$. The shortest panicle length was recorded by NSIC RC 272 with $17.66 \mathrm{~cm}$. Again the highly significant difference was attributed to the different plant characteristics.
On crop management means, there exist highly significant difference. Plant respond to RCM+ in terms of panicle length with a mean of 24.64. This was followed by control, FP and RCM as second rankersince no significant difference between them. This means that plant with longer panicles of rice were obtained in RCM+. According toYoseftbar (2013) as cited by ( wei et al, 2011) that nitrogen can increase the grain yield by increasing the total dry matter production, the number of panicles and the panicle length of lowland rice. Additionally, nitrogen application increases the panicle weight, number of grains per panicle, 1000- grain weight and hence the grain yield of rice (Vennila et al, 2007). Again, no interaction existed between the 15 varieties and crop management. 


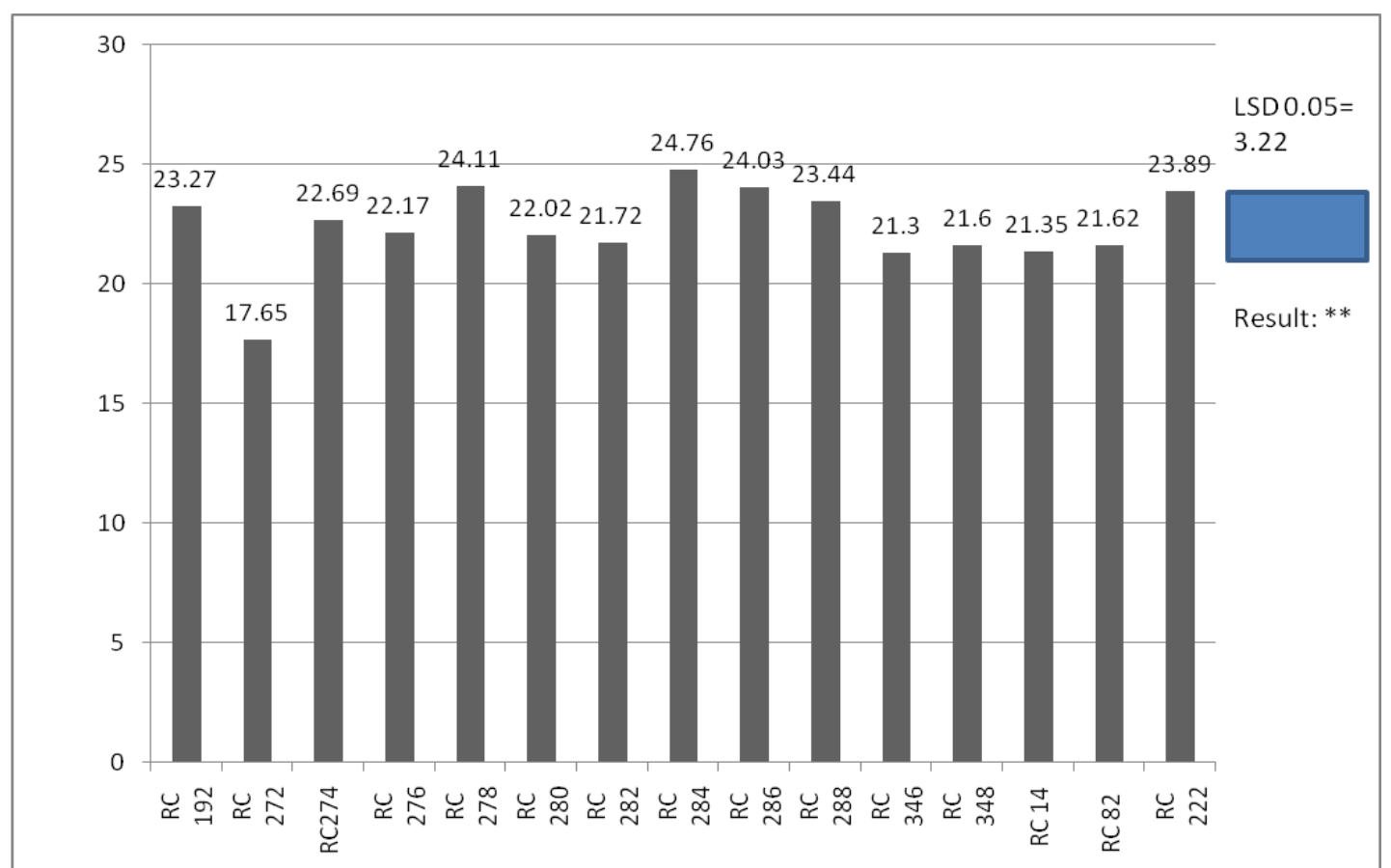

Figure 6a: The panicle length performance of the 12 rainfed rice genotypes including 3 checks (PSB RC 14, PSB RC 82 and PSB RC 22) across the four crop management (Control, Farmers Practice, Rice Crop Manager and Rice Crop Manager+).

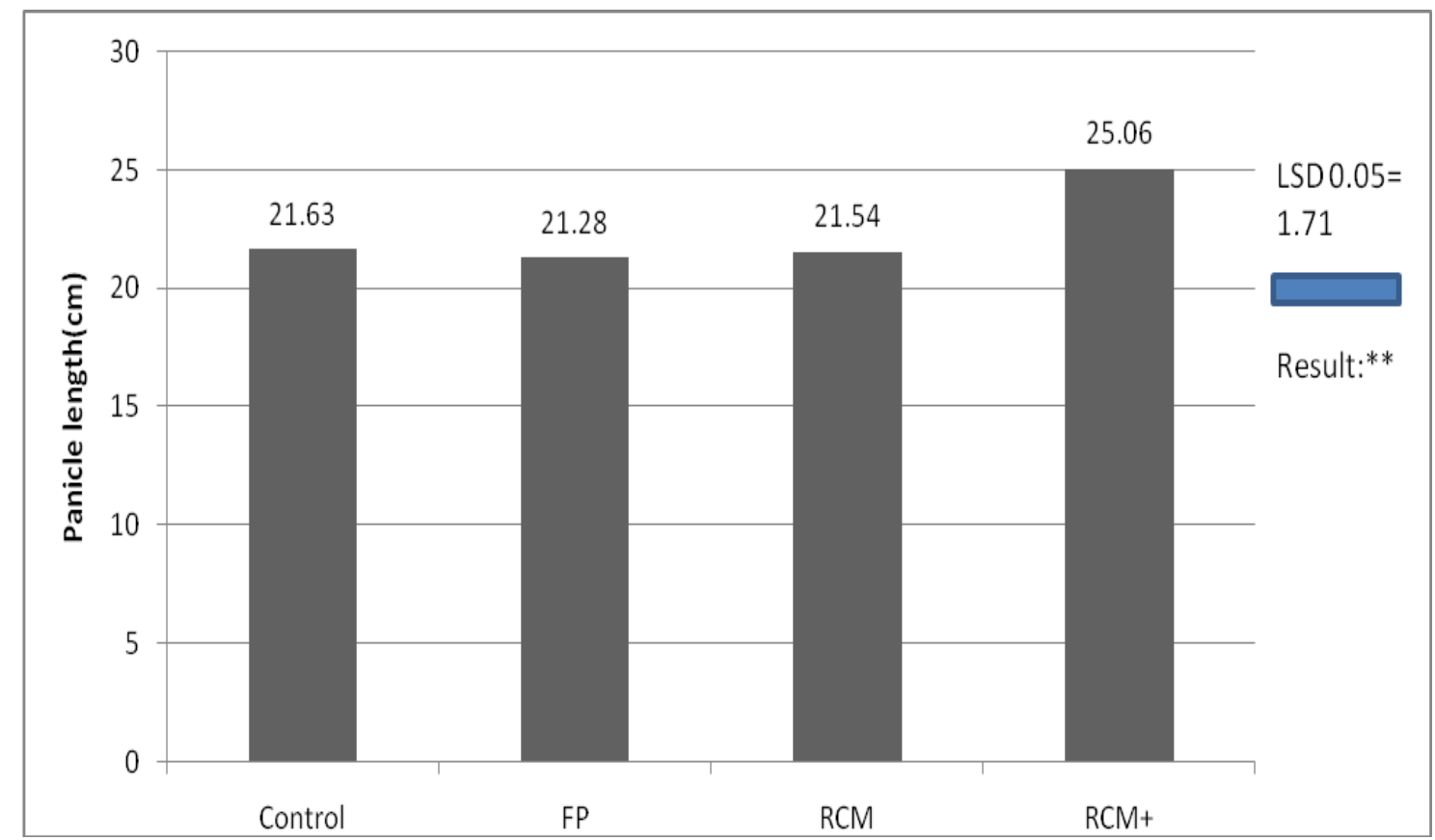

Figure 6b: Performance of the four crop management on panicle length across the 12 rainfed rice genotypes including 3 checks (PSB RC 14, PSB RC 82 and PSB RC 222). Where FP:Farmers Practice, RCM: Rice Crop Manager, and RCM+:Rice Crop Manger plus. 


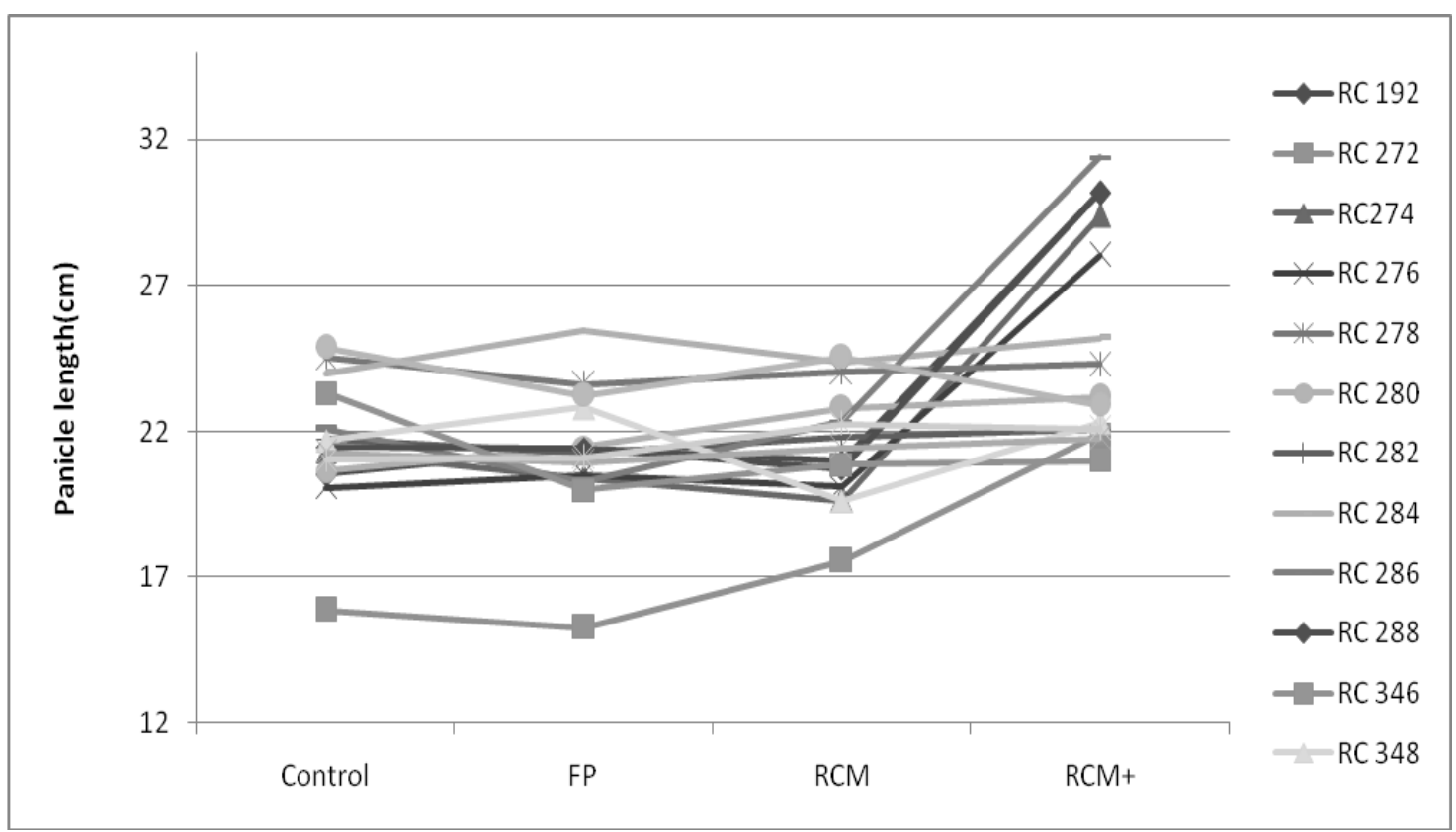

Figure 6c: Interaction of panicle length performanceof the 12 rainfed rice genotypes including 3 checks (PSB RC 14, PSB RC 82 and PSB RC 222) to four crop management (Control, Farmers Practice, Rice Crop Manager and Rice Crop Manager+).

\section{Yield tons/ha}

Analysis and graphs are still on the process...

\section{Grain weight (g)}

Figure shows the weight of 1000 grains of the 12 rainfed rice genotypes including 3 checks (PSB RC 14, PSB RC 82 and PSB RC 222) across the four crop management Control, FP,RCM and RCM+. Analysis of variance revealed that there exist highly significant differences. Among the varieties means, NSIC RC 288, NSIC RC 286,NSIC RC 284, NSIC RC 348 and NSIC RC 278 obtained the heaviest grains ranging from 26.04 to 26.89 grains. This was followed by NSIC RC 346 and NSIC RC 282 of 25.99 and 25.69 grains respectively. Third ranker varieties was recorded from NSIC RC 274, NSIC RC 222, NSIC RC 280, NSIC RC 276 PSB RC 82 and PSB RC 14 of 22.87 to 25.03 grams. NSIC RC 192 obtained $4^{\text {th }}$ placed with a mean of 21.68 . NSIC RC 272 has the lightest mean of 20.91 .

In terms of crop management means analysis of variance reveals no significant differences. No interaction between variety to crop management was also obtained 


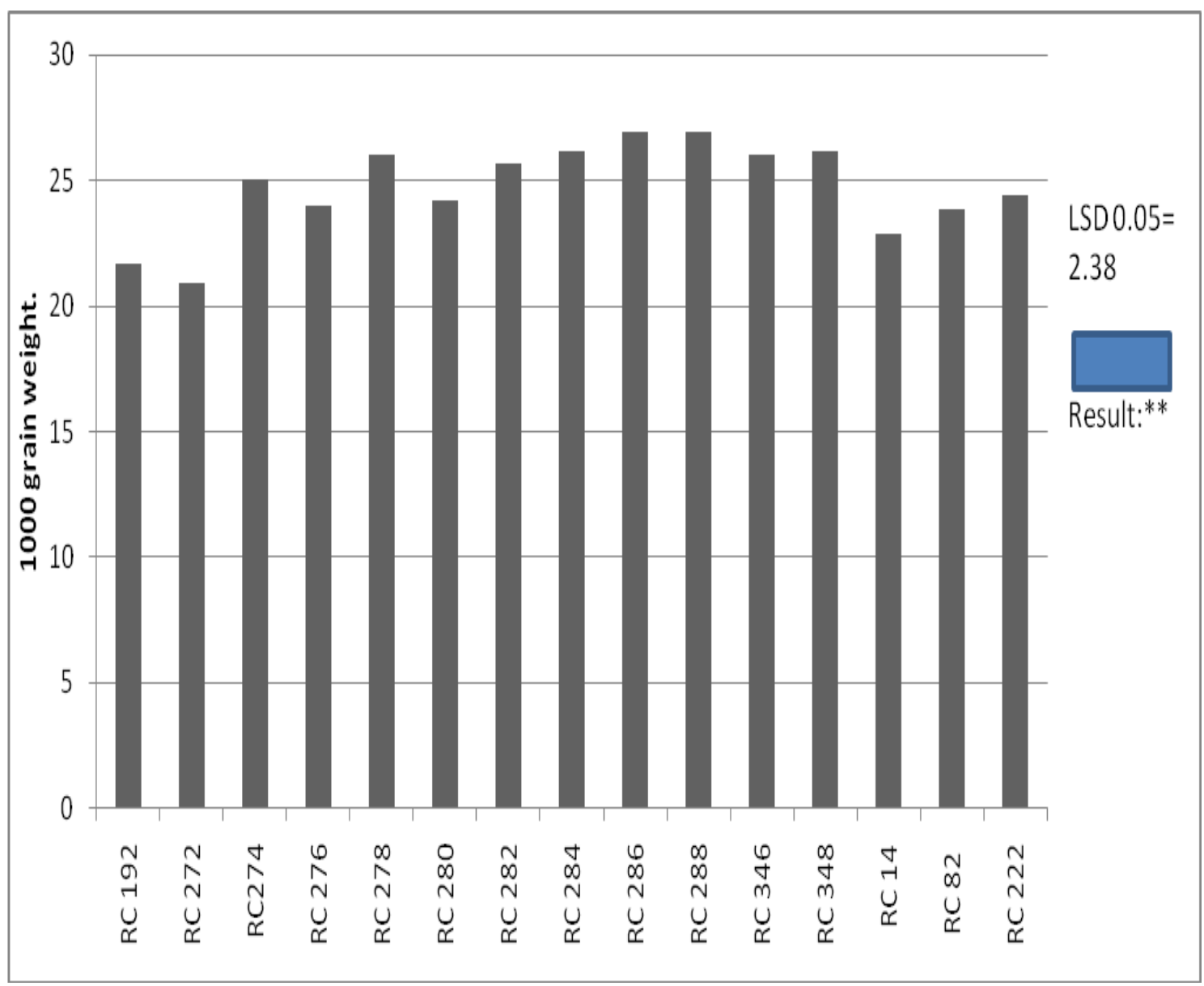

Figure 7a.1000 grain weigth of the 12 rainfed rice genotypes including 3 checks (PSB RC 14, PSB RC 82 and PSB RC 222) across the four crop management Control, Farmers Practice, Rice Crop Manager and Rice Crop Manager+). 


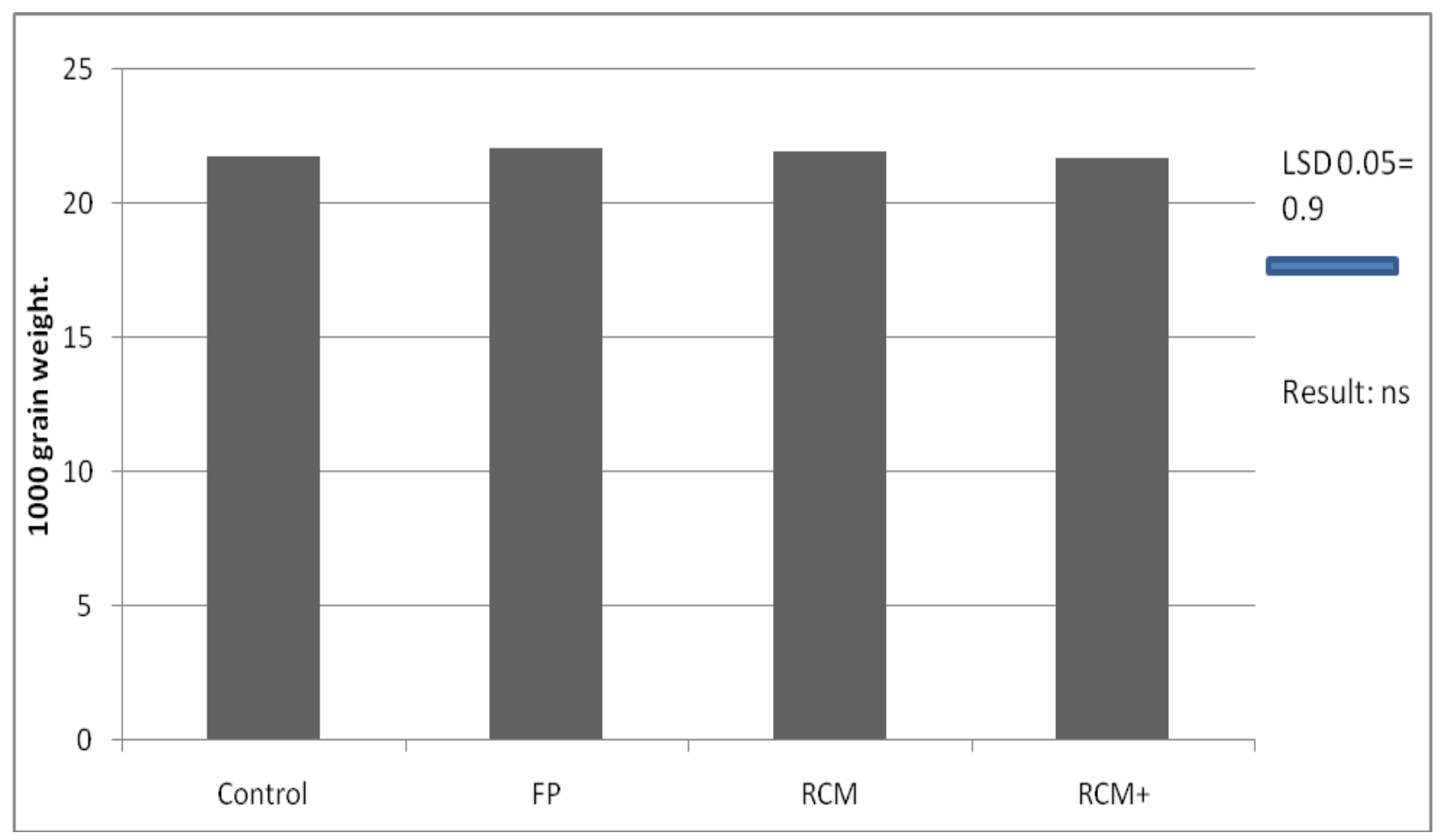

Figure 7a.1000 grain weigthof the 12 rainfed rice genotypes including 3 checks (PSB RC 14, PSB RC 82 and PSB RC 222) across the four crop management Control, Farmers Practice, Rice Crop Manager and Rice Crop Manager+).

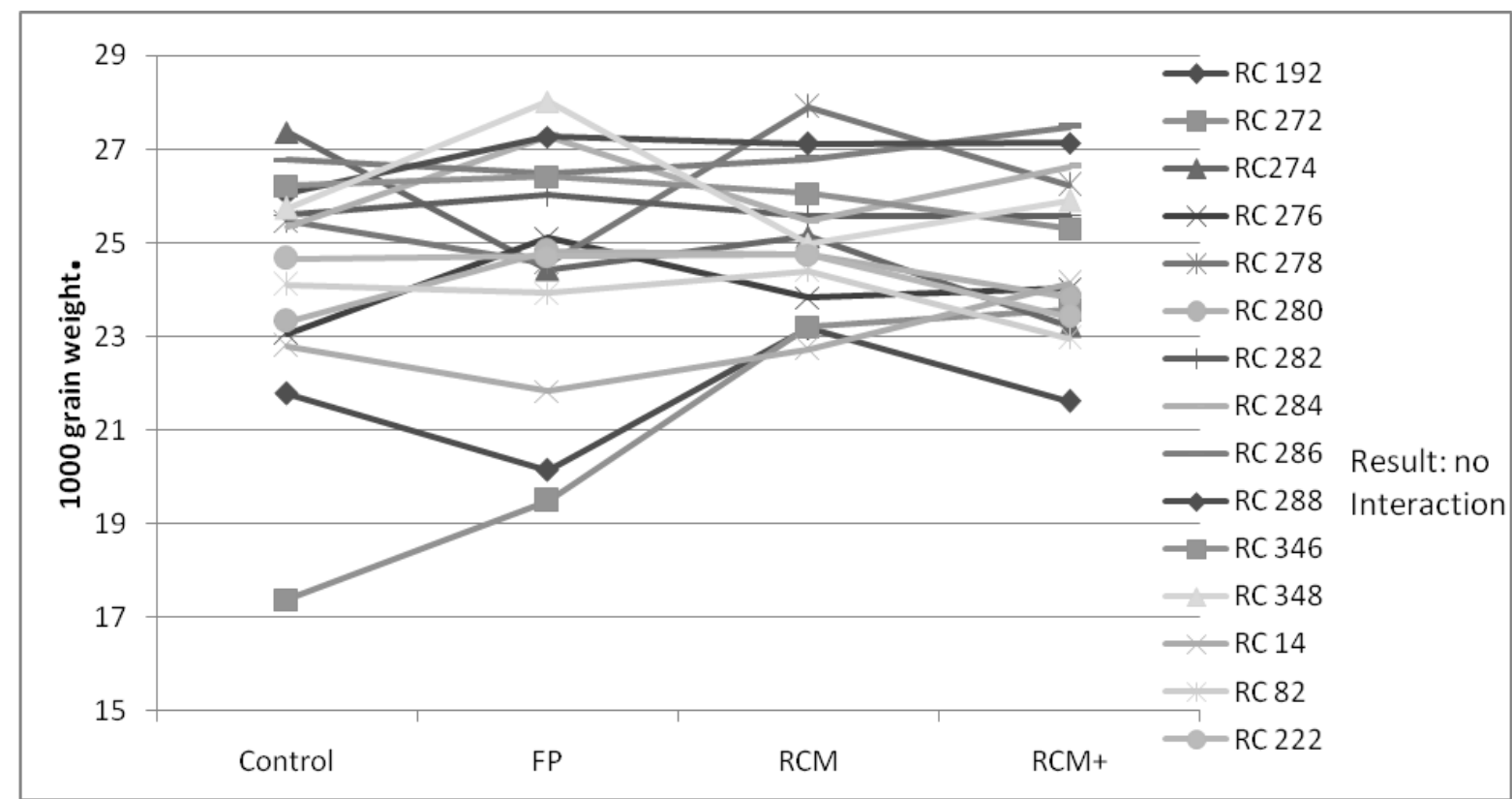

Figure 7c: Interaction of the 12 rainfed rice genotypes including 3 checks (PSB RC 14, PSB RC 82 and PSB RC 22) to four crop management (Control, FP,RCM and RCM+) on 1000 grain weight. 


\section{Percent fertility}

Figure shows percentage fertility of the 12 rainfed rice genotypes including 3 checks (PSB RC 14, PSB RC 82 and PSB RC 222) across the four crop management Control, FP, RCM and RCM+. Based on the analysis of variance, there is no significant differences between variety means. This means that all varieties has almost the same number of fertile seeds.
The same result in terms on the crop management. This means that the different crop management has no bearing in the production of fertile seeds.

No interaction was also obtained the between variety and nutrient management.

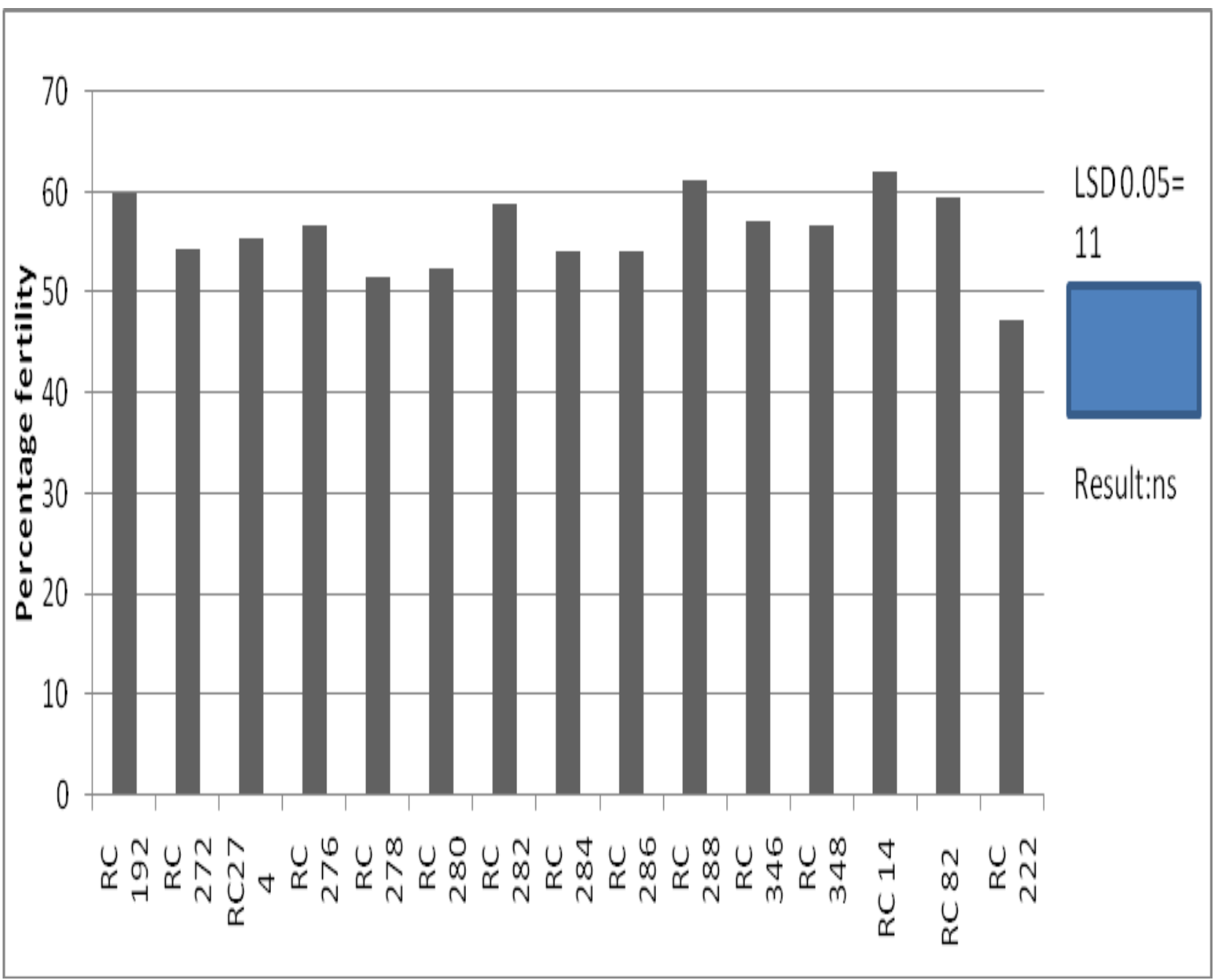

Figure 8a. Percentage fertility of the 12 rainfed rice genotypes including 3 checks (PSB RC 14, PSB RC 82 and PSB RC 222) across the four crop management Control, Farmers Practice, Rice Crop Manager and Rice Crop Manager+). 


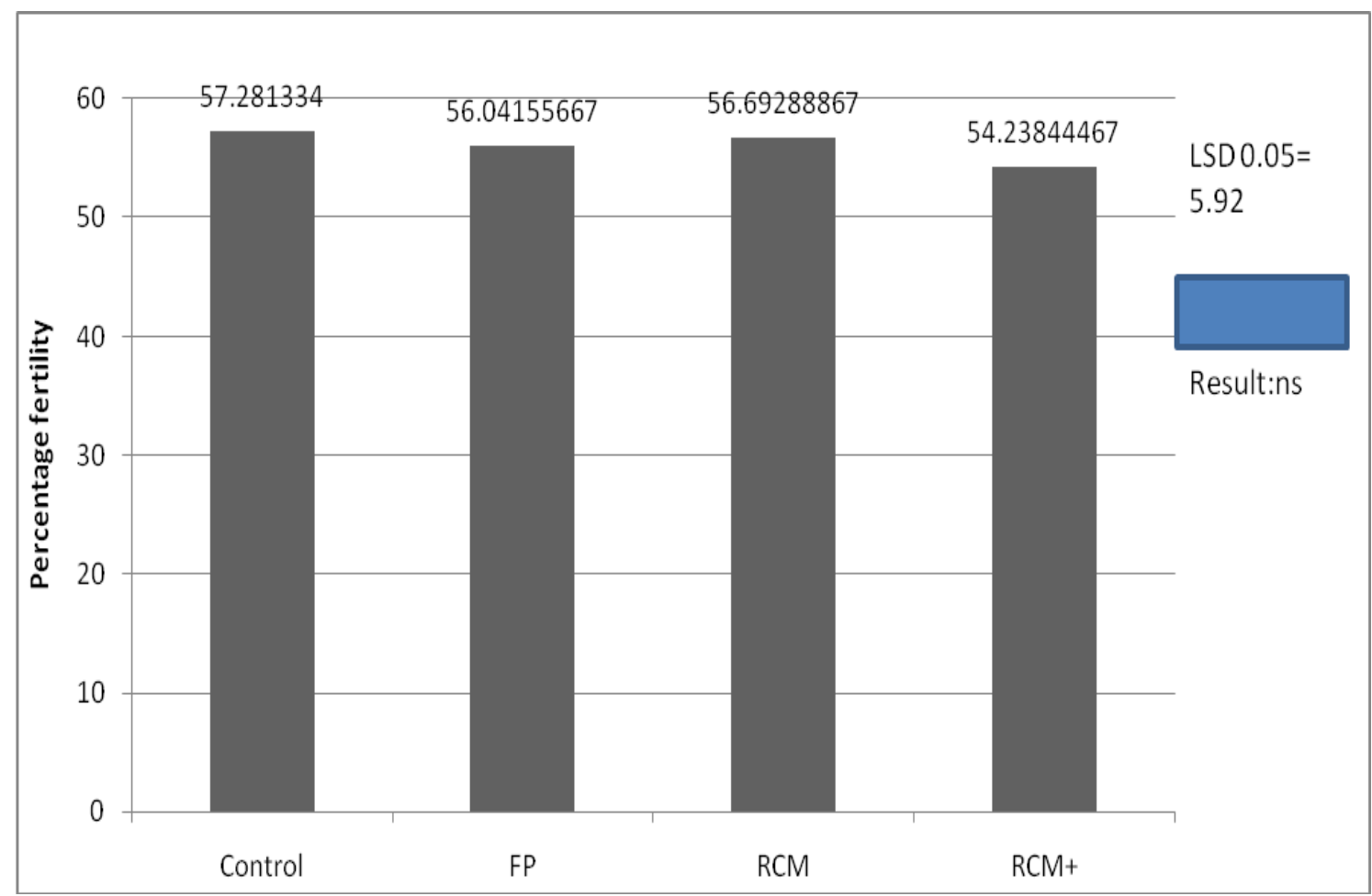

Figure 7a.Percentage fertility of the 12 rainfed rice genotypes including 3 checks (PSB RC 14, PSB RC 82 and PSB RC 222) across the four crop managements (Control, FP, RCM and RCM+) on percentage fertility. Where: $\mathrm{FP}=$ farmers practice; $\mathrm{RCM}=$ rice crop manager; $\mathrm{RCM}+=$ rice crop manager plus.

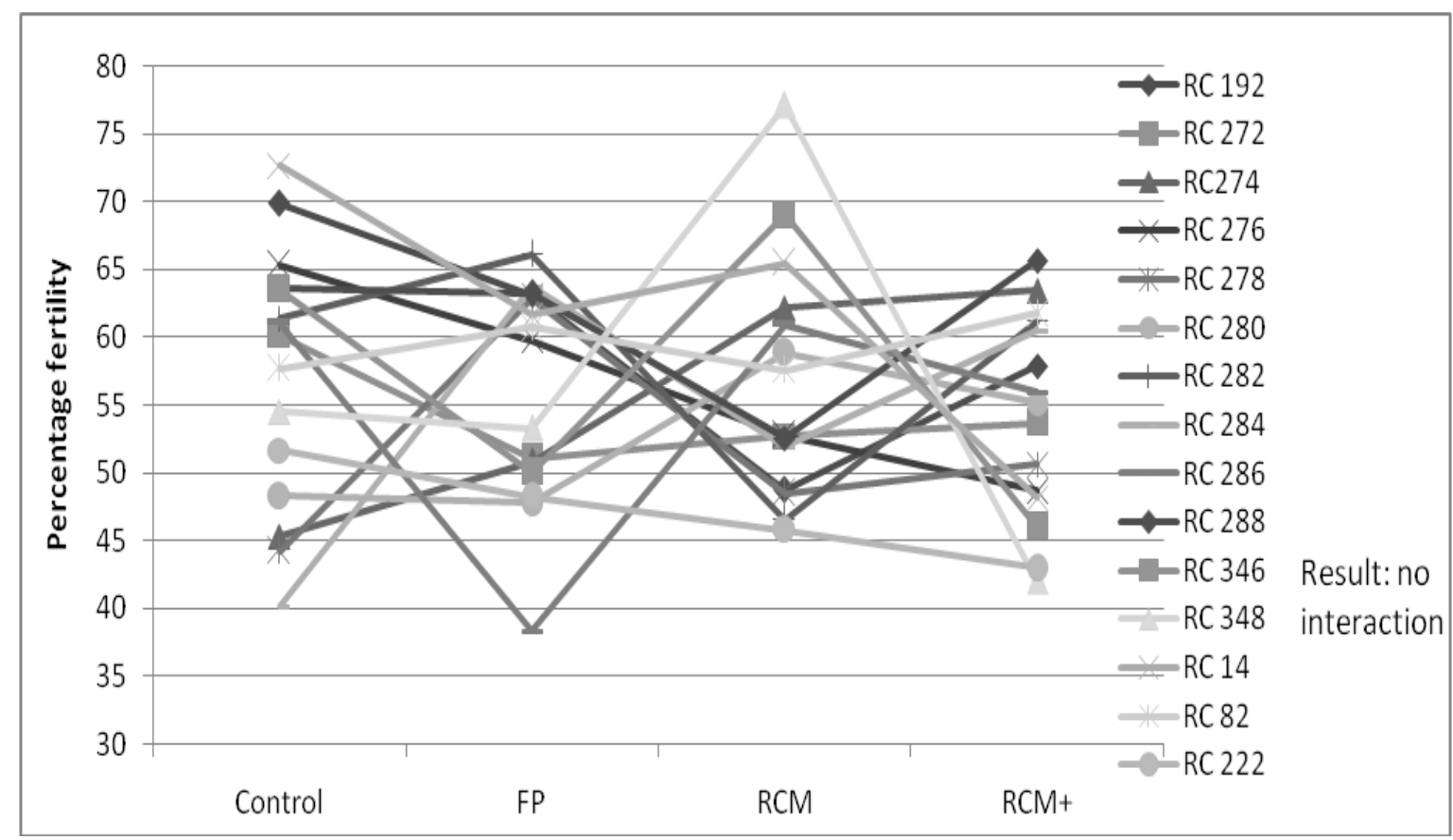

Figure 5c: Interaction of the 12 rainfed rice genotypes including 3 checks (PSB RC 14, PSB RC 82 and PSB RC 22) to four crop managements (Control, FP, RCM and RCM+) on percentage fertility. Where: FP=farmers practice; $\mathrm{RCM}=$ rice crop manager; $\mathrm{RCM}+=$ rice crop manager plus. 


\section{CONCLUSION}

Based from the results of the study, there were significant differences in yield attributed to varietal and genetic differences of materials tested. NSIC Rc284 having obtained the highest yield of 4.2 ton/ha with maturity of 110.67 days and NSIC Rc288 and NSIC Rc276 with yields of 3.89 and 3.88 ton/ha with maturity of 94 and 92 days respectively were the $2^{\text {nd }}$ highest yielder which means that these are the selections specifically adapted at CSU Piat condition.

\section{RECOMMENDATION}

The top 3 selections NSIC Rc284, NSIC Rc288, and NSIC Rc276 are specifically adapted at CSU
Piat condition which will provide farmers an option of increasing yield and income using the right rainfed variety even in highly variable rainfed ecosystem, thus it is highly recommended to farmers.

\section{LITERATURE CITED}

Anderson J, Churchill G, Autrique J, Tanksley S, Sorrells M. 1993. Optimizing parental selection for genetic linkage maps. Genome 36:1187-1195.

Collard BCY, Pang ECK, Taylor PWJ. 2003. Selection of wild Cicer accessions for the generation of mapping populations segregating for resistance to ascochyta blight. Euphytica 130:1-9. 